\title{
THE EFFECT OF ALL-TRANS RETINOIC ACID AND FATTY ACIDS ON MCF-7 BREAST CANCER CELL PROGRESSION
}

\author{
A Thesis \\ presented to \\ the Faculty of California Polytechnic State University, \\ San Luis Obispo
}

In Partial Fulfillment

of the Requirements for the Degree

Master of Science in Agriculture, with Specialization in Food Science and Nutrition

\section{By}

David Adam Brown

October, 2009 
(C) 2009

David Adam Brown

ALL RIGHTS RESERVED

COMMITTEE MEMBERSHIP 
TITLE:

AUTHOR:

DATE SUBMITTED:

COMMITTEE CHAIR:

COMMITTEE MEMBER:

COMMITTEE MEMBER:
The Affect of All-trans Retinoic Acid and Fatty Acids on MCF-7 Breast Cancer Cell Progression David Adam Brown

October, 2009

Susan Hawk

Scott Reaves

Lisa Nicholson

ABSTRACT

The Affect of All-trans Retinoic Acid and Fatty Acids on MCF-7 Breast Cancer Cell Progression 


\section{David Adam Brown}

Vitamin A metabolites and retinoids may slow the progression of breast cancer and elicit anti-neoplastic properties similar to those of omega-3 fatty acids. Studies using animal models show a decrease in the incidence, growth and metastisis of mammary tumors in the presence of specific fatty acids. This effect is also seen with use of retinoids, specifically all-trans retinoic acid (AtRA). Thus, fatty acids may also alter retinoid homeostasis in mammary carcinoma cells (MCF-7s). The potential for inter/co dependency among fatty acids and retinoids is considerable, and here it has been hypothesized that a decrease in cancer progression will occur in the presence of both compounds. MCF-7's were seeded in a 48 well plate at 5,000 cells per well. After $24 \mathrm{hr}$, cells were treated with either $1 \mu \mathrm{M}$ AtRA alone, fatty acids alone, or AtRA + fatty acids. Fatty acid treatments (Linoleic, and Linolenic) were administered at 2.5 uM concentrations. Each fatty acid treatment was also combined with $1 \mu \mathrm{M}$ AtRA to determine if there is a synergistic effect on slowing cell growth. Both culture media and treatments were changed at 24 hour intervals over a 3 day trial. When compared to the controls, cells treated with $1 \mu \mathrm{M}$ AtRA or $2.5 \mu \mathrm{M}$ Linolenic acid both inhibited cell growth. Interestingly, when combined with Linolenic acid, AtRA treatment resulted in a significant (nearly 50\%) additional growth inhibition when compared to treatment with AtRA alone. Our results suggest that AtRA and Linolenic acid have a inter/co dependency that significantly inhibits breast cancer cell growth in vitro by $73.4 \%$ compared to control, and $49.7 \%$ compared to AtRA alone over 72 hours. We conclude 
that AtRA and linolenic acid have a combined effect in breast cancer cell proliferation invitro and their role in dietary prevention warrants further investigation.

\section{ACKNOWLEDGEMENTS}

While there were many people involved in the completion of this thesis, I will simply name a few. Lisa Nicholson, Scott Reeves, and Susan Hawk-Woody were incredibly gracious with their time and effort in helping me succeed. Thank you for every moment you provided me over the last couple years. I would like to extend my sincere gratitude to Jessica Yee and Diana Rios for being incredible lab partners, and always helping me succeed. Dan Peterson was my greatest inspiration as a professor, and taught 
me the meaning of responsibility. My wife Michelle was unwavering, even in the tough moments. Finally, I would like to dedicate the completion of this thesis to my late father. Thank you Dad.

\section{TABLE OF CONTENTS}

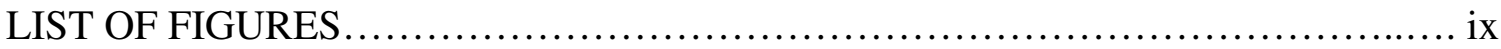

\section{CHAPTER}

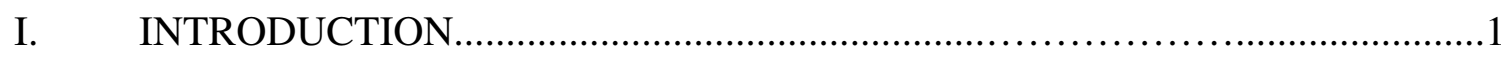

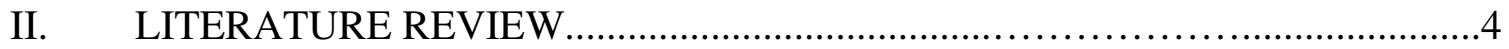


2.1: Breast Cancer........................................................... 4

2.2: Retinoic Acid and Breast Cancer...................................... 9

2.3: Fatty Acids and Breast Cancer........................................ 12

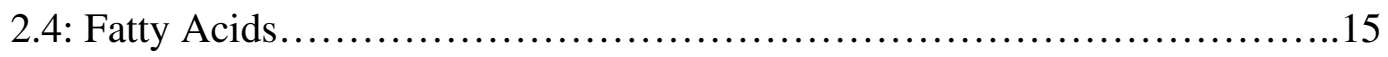

2.4.1: Omega 3 Fatty Acids............................................ 16

2.4.2: Omega 6 Fatty Acids........................................... 17

2.4.3: Monounsaturated Fatty Acids...................................18

2.4.4: Conjugated Linoleic Acid........................................19

2.4.5: Trans Fatty Acids..............................................19

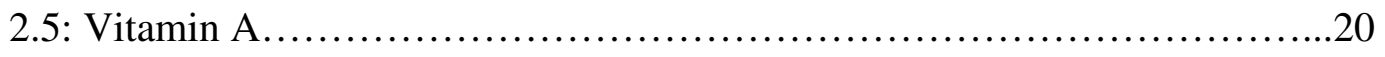

2.6: Nuclear Hormone Receptors...........................................25

2.7: Nutrient Delivery System...........................................27

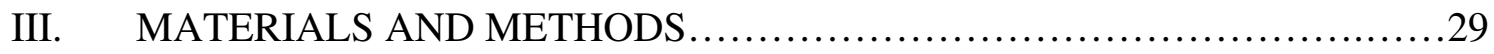

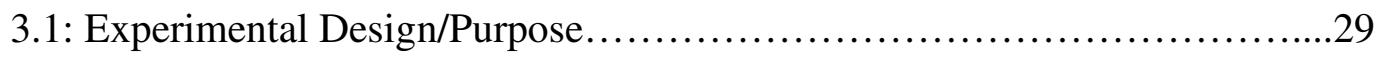

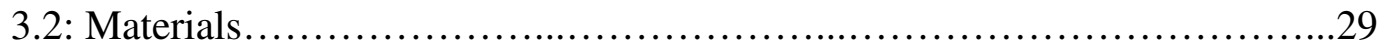

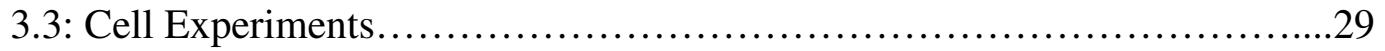

3.4: Cell Treatments................................................... 30

3.5: Cell Proliferation Assay ................................................... 31

3.6: Cell Proliferation Quantification...........................................31

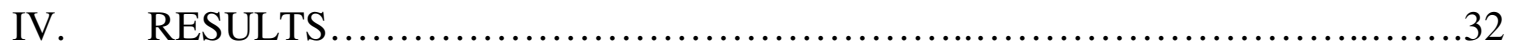

4.1: AtRA and Linolenic Acid Combined Treatment Results.....................35

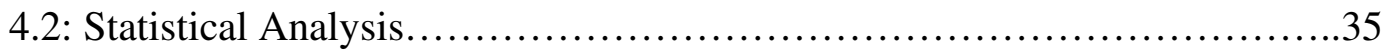

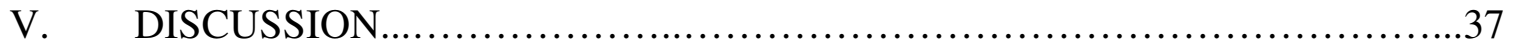

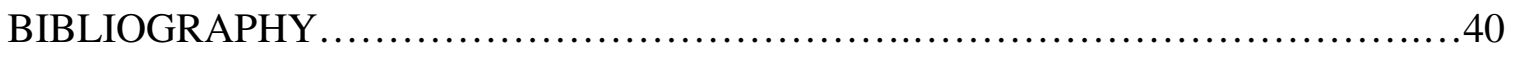


Appendix A: Cyquant Cell Proliferation Protocol $\ldots \ldots \ldots \ldots \ldots \ldots \ldots \ldots \ldots \ldots \ldots \ldots \ldots . \ldots 45$

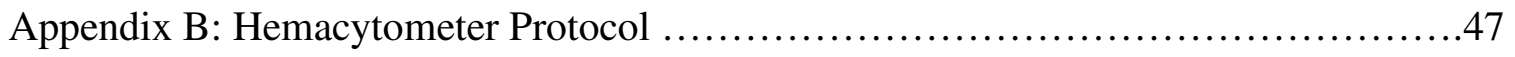

Appendix C: Complete Expanded Results ....................................48

Appendix D: Liposome Delivery System Results.............................51

Appendix E: Minitab Output.................................................53

\section{LIST OF FIGURES}

2.1.1 Image of Chromosome 17, and Chromosome 13, with location of BRCA1 and

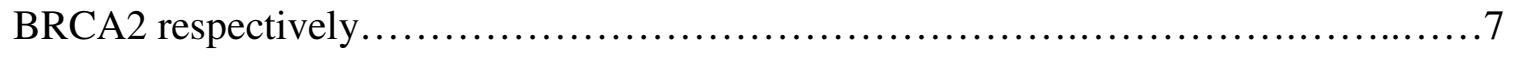

2.2.1 RXR partner binding sites......................................... 12

2.5.1 Retinol conversions (a) and binding sites (b) intracellularly...................22

2.6.1: PPAR alpha and gamma pathways......................................

3.1: View of hemacytometer grid (10x) and cells. Cells are counted in the squares and determine the amount of cells in solution following calculation......................30

4.1: Molecular Probes Cyquant Kit: AtRA...................................... 32 
4.2: Cell Proliferation Assay. Standard curve for cell growth under varying amounts of

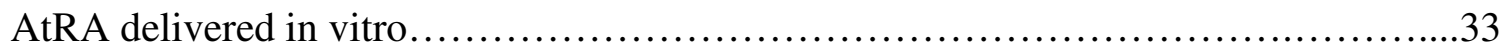

4.3: Cell Proliferation Assay: Data presented as percent of control.....................34

4.4: Molecular Probes Cyquant Kit: 72 hours, AtRA and Fatty Acids...................34 4.5: AtRA refeeding is significantly more effective at decreasing MCF-7 cell growth over 72 hours compared to a single treatment.......................................... 


\section{Chapter 1}

\section{INTRODUCTION}

All-trans retinoic acid (AtRA), the intracellular derivative of vitamin $\mathrm{A}$, has been shown to slow the progression of human mammary carcinoma cells (MCF-7) in vitro (Danforth 2004, Cho et al. 2007). Of perhaps equal importance is the role by which fatty acids contribute to tumor growth and stability. With both AtRA and intracellular fatty acid involvement with the nuclear hormone family of receptors, the possibility of synergism is substantial. Interestingly, altered nuclear receptor activity is known to increase carcinogenesis (Chamras et al. 2002). In either situation, both retinoids and fatty acids are directly involved with the cells ability to undergo apoptosis (Okamoto et al. 2000)

AtRA is responsible for cell growth, differentiation, and apoptosis (Liu et al. 1996). This control is mediated via hormone receptors in the nucleus. MCF-7 cells have shown diminished hormone receptor efficiency which results in a decreased availability of AtRA. The result is a reduced amount of a ligand which promotes apoptosis via genetic transcription (Budhu 2002). The steroid-thyroid receptor super-family includes the retinoic acid receptor (RAR and RXR), which also includes receptors for estrogen and vitamin D (Tighe 2004). Recently, it has been shown that many carcinogenic cell types are missing retinoic acid receptors. Because retinoic acid seems to induce apoptosis, an accumulation of receptor deficient cells could be unresponsive to normal retinoic acid levels and therefore not undergo normal cellular death required for optimal health of the organism (Merino 2003). There are many pathways involved in this process and include those involving fatty acids. 
Fatty acids have been under extreme scrutiny for their involvement in breast cancer incidence and progression. Both the protective effects of omega-3 fatty acids (linolenic), and the enhancing effects of omega-6 fatty acids (linoleic) have been demonstrated in the literature (Cohen et al. 1986, Chajès et al. 1995). While there is yet to be substantial evidence to directly link linoleic acid to breast cancer in vivo, animal studies, which have shown diminished breast cancer progression as a consequence of linolenic acid treatment (Reyes et al. 2004). Epidemiological studies also link fish oil, a classic source of omega-3, intake with lower breast cancer incidence (Rose 1999). Peroxisome proliferator-activated receptors (PpAR), members of the nuclear hormone signaling family are directly involved with breast cancer tumorogenesis (Thoennes et al. 2000). Interestingly, Linolenic acid acts as an agonist to this receptor and therefore has yielded increased apoptosis in MCF-7 cells (Menendez et al. 2001). Using this acid presents a viable option to creating new and effective cancer treatments and establishing preventative lifestyle behavior choices.

Separate investigations have confirmed the use of both AtRA and Linolenic acid to slow breast cancer proliferation in vitro by establishing a higher rate of apoptosis (Liu et al. 1996, Budhu 1996). Here, we combine the two treatments to investigate the synergism. We show that physiological treatments of both AtRA and linolenic acid further increase apoptosis when compared to each treatment alone. We believe the explanation is found on the surface of the nucleus where nuclear transporters are changed dramatically in a carcinogenic cell. The PpARy receptor and RXR receptor act together as a dimer and have a unique response element (PpARE) (Kim 2003). Up-regulation of this genetic activity seems to slow cancer proliferation, and is a viable explanation for our 
observation of AtRA and linolenic acid as cancer treatments in vitro. Clearly, the functional significance of these findings will require further investigation.

\section{Chapter 2}




\section{LITERATURE REVIEW}

\subsection{Breast Cancer}

Breast cancer is the second leading cause of death from cancer among American women (Reyes et al. 2004). It is estimated that 217,440 new cases of this cancer was diagnosed, and over 40,000 deaths occured in 2005 alone (Reyes et al. 2004). Age is one of the strongest risk factors in breast cancer. In women under the age of 30, breast cancer is very uncommon. The incidence rate begins to increase between ages 35 and 39 years and does not plateau until age 80 (Reyes et al. 2004). Breast cancer incidence is also influenced by race. In the United States, breast cancer risk is slightly higher in whites than in African Americans, although the incidence of early-onset cancers is higher in African Americans (Kuhajda 2000). Incidence rates are markedly lower in other racial and ethnic groups (Korde et al. 2004). The most common types of breast cancer occur in the lining of the ducts or in the lobules of the breast. Atypical ductal hyperplasia results in an overactive growth of cells lining the breast ducts, while lobular carcinoma results in uncontrolled growth of lobular cells.

On average, women have a $10 \%$ to $14 \%$ chance of having breast cancer by the time they reach 90 years of age (Reyes et al. 2004). Women at increased risk may have a strong family history of breast cancer, a known or suspected genetic predisposition for the disease, a history of radiation therapy, a previous problem of the breast, and a 5-year Gail model risk of $1.67 \%$ or greater (Murff et al. 2004).

There are two types of models used in breast cancer risk assessment--those that estimate the risk of breast cancer over time and those that estimate the risk of a mutation in one of the BRCA genes. These models are the Gail and Claus models, respectively. The 
current version of the Gail model estimates the 5-year and lifetime risks of breast cancer by incorporating risk factors such as age, age of menarche, and age of $1^{\text {st }}$ pregnancy. A 5year risk of $1.67 \%$ is considered elevated risk (Korde et al. 2004). The Gail model has proven to be very limited as it fails to incorporate paternal family history and ovarian cancer family history (Murff et al. 2004). In contrast, the Claus model is useful because it bases risk on family history of breast and ovarian cancers on both the maternal and paternal lineage. These two models compliment each other well, and together help women to define their risk of developing breast cancer. Defining risk can also prepare both physicians and patients for effective treatment. The only true shortcoming of these models is the continuing evidence that breast cancer is simply a mutation on the genome.

Breast cancer treatments vary depending on the advancement of the cancer, and the patient's response to each treatment. The best opportunity to reduce mortality is through early detection (Maggiora et al. 2004). Generally, the location and size of the tumor in the breast and the extent of the disease in the armpit and the rest of the body will determine treatment options. Breast cancer progresses in stages. Stages 0-II are termed early stages, where the severity is a small tumor 1-2 inches in diameter with little or no lymph node invasion. Stage III is a progression towards the complete metastatic invasion known as type IV. The final stage is the most severe and advanced because of the extensive tissue invasion and malignancy (Maggiora et al. 2004). To develop a treatment plan to fit each patient's needs, the doctor also considers the woman's age and general health, as well as her feelings about the treatment options. The primary method of treatment is surgery. Few patients elect to bypass this option, as it is considered necessary to stop the cancer progression. The lumpectomy procedure removes a tumor from the breast, while a 
mastectomy removes a portion of, or the entire breast. The need of the mastectomy is based on the progression of the cancer, and the literal "spread" of the cancer. This depends on the number of tumors in the area, as well as the condition of the local lymphnodes (Wiseman 2004).

The second step in treating cancer is radiation therapy, which uses $\mathrm{x}$-rays and other radioactive materials to kill cancer cells. The radiation disrupts cell growth by destroying DNA and cell membranes (Serrano et al. 2004). This can be performed externally or internally depending on the growth of the cancer, and is effective when the cancer can be targeted in a specific area of the body.

The third step is chemotherapy, which is the use of chemical agents to either destroy dividing cells or stop their division. Chemotherapy can be localized, but in general is a systemic treatment. Gleevec, a pharmaceutical agent, inhibits cancer cell growth by inducing apoptosis. It binds to abnormal proteins in cancer cells, blocking uncontrolled cell growth. Because it binds only to these abnormal proteins, Gleevec does not show the high levels of toxicity exhibited by other chemotherapy drugs (Abou-Jawde et al. 2003).

The fourth and final treatment step is the use of hormone therapy. Hormone therapy can be used throughout the entire treatment process; however it is only applicable for certain types of breast cancer. In 1998, the Food and Drug Administration approved Nolvadex (tamoxifen citrate), which interferes with the activity of estrogen to reduce the incidence of breast cancer in women at high risk for developing the disease (Merino et al. 2003). It is used as an additional type of therapy in conjunction with other steps in fighting the cancer (Abou-Jawde et al. 2003). The anti-proliferative effects of Tamoxifen 
have been attributed to the inhibition of protein kinase $\mathrm{C}$ and its calmodulin binding (Abou-Jawde et al. 2003). The activity of these proteins is directly connected to the known breast cancer susceptibility genes.

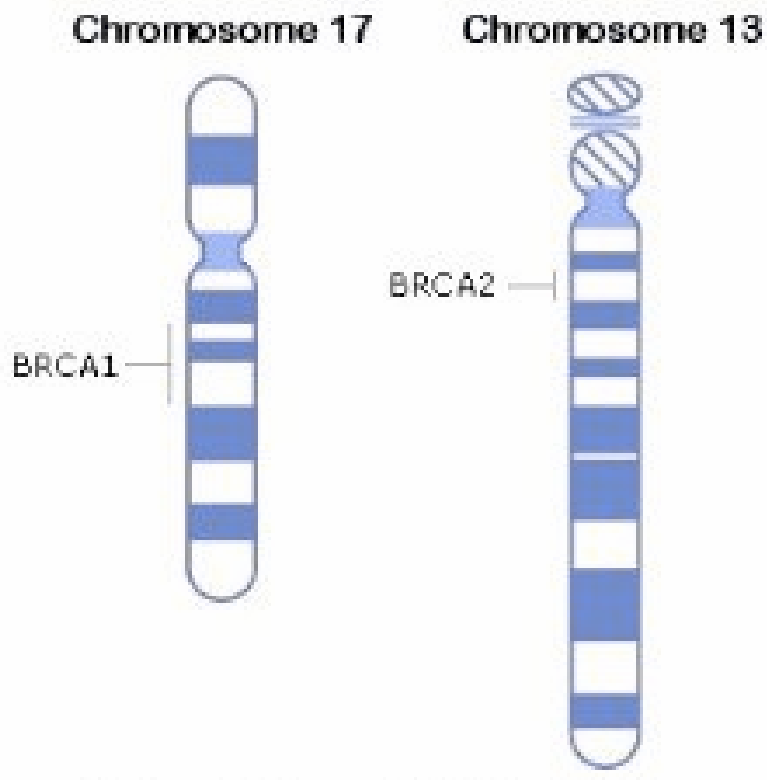

Figure 2.1.1. Image of Chromosome 17, and Chromosome 13, with location of BRCA1 and BRCA2 respectively (National Library of Medicine, NCBI, www.son.wisc.edu).

Two breast cancer susceptibility genes have been identified. BRCAl was found on chromosome 17 and BRCA2 was found on chromosome 13 (Serrano et al. 2003). When either gene has a mutation there is an increased risk of developing breast cancer and/or ovarian cancer. The genes were discovered in 1994, and until recently researchers were not able to identify their function (Abou-Jawde et al. 2003). A yeast study revealed that they repair radiation-induced "gaps" in double-stranded DNA. A mutant form of these genes causes these "gaps" to progress into tumor growth (Abou-Jawde et al. 2003). Human epidermal growth factor receptor 2 (HER2) along with the p53 gene have also 
been shown to be causative factors when their mutations lead to breast cancer (AbouJawde et al. 2003).

Lifestyle choices are a very important area of interest when determining possible sources of cancer development. Dietary influences have been heavily explored as of late, and have produced many promising links between diet and cancer. Vitamin A (retinoids) has been shown to play a major role in the progression of breast cancer cells in vitro (Merino et al. 2003). This important vitamin can change its role on the molecular level when not readily converted to its active form (retinoic acid) and leads to unnatural control over the human genome yielding cancerous growth. Scientists currently believe that the link between fatty acids and breast cancer is also substantial. Saturated fatty acids have been termed carcinogenic for some time, and omega 6 fatty acids seem to be following that trend and have been linked to breast cancer incidence (Thoennes et al. 1999).

On the contrary, antioxidant-rich foods protect normal cellular growth processes. Polyphenols, vitamin C, and Vitamin E have been toted as the great cancer preventors. While studies show these factors to be greatly protective against oxidative and free radical damage, there is little evidence to support these facts on the molecular and genomic level for breast cancer (Mezzetti 2001). While scientists may not argue against having a vegetable rich diet to help prevent cancer, the conclusive evidence for such has yet to be uncovered.

Diet is not the only lifestyle choice influencing cancer risk. Epidemiologic data regarding physical activity suggest a $20 \%$ to $30 \%$ reduction in the risk of breast cancer in women who are physically active compared with those who are inactive (Wiseman 2004). In addition, moderate to heavy alcohol intake (more than $45 \mathrm{~g}$ of alcohol, or three 
drinks, per day) has been shown to increase the risk of cancer, in a dose-response relationship (Wiseman 2004). High alcohol consumption causes the liver to be less effective at controlling estrogen levels in the body. This results in increased estrogen exposure to cells, and an increase in the chance of cancerous cell growth.

High levels of hormones, particularly estrogens, have been shown to be associated with increased breast cancer occurrences (McClelland 2004). Another theory claims that breast cancer progresses over time, and only becomes a clinical disease later in life (Wiseman 2004). The decisions women make regarding different hormone therapies influence breast cancer risk. These decisions include the use of oral contraceptives, excessive exercise, and hormone replacement therapy. The increased exposure of breast tissue to estrogen during these treatments has a direct link as a risk factor. The use of hormone replacement therapy for the difficulties of menopause has also been shown to increase cancer susceptibility from 5-40\% (Wiseman 2004). Oral contraceptive use has been controversial about its potential increase in breast cancer risk. However, the most recent data suggests that oral contraceptive use is not associated with increased risk of breast cancer (Korde 2004).

\subsection{Retinoic Acid and Breast Cancer}

The vitamin A metabolite retinoic acid (RA) and its derivatives are effective chemotherapeutic agents in the treatment of a number of types of cancer, including tumors of lung, breast, head and neck, and blood (Sun et al 1997). The historical and most significant finding to date has been the use of retinoids to treat acute promyelocytic leukemia (APL) (Jimenez-Lara et al. 2004). Along with chemotherapy, the prognosis for 
the disease has improved rapidly. In animal models, retinoids have antitumor activity in cancer xenografts and induced regression of mammary carcinoma (Lehmann et al. 1991). In vitro, RA and its derivatives inhibit proliferation of a variety of tumor types including lung, breast, leukemia, and rhabdomyosarcoma (Lehmann et al. 1991). Retinoids exert their function on tumor growth in three ways: increased cellular differentiation, decreased cell proliferation, and induction of apoptosis (Merino et al. 2004). Retinoids are known to inhibit hormone dependent, but not hormone independent mammary carcinoma cells (Liu et al. 1996). Thus, retinoids are currently being used as a treatment for many epithelial cancers (Liu et al. 1996).

Retinoic acid receptors (RAR) and RA in cancer therapy was initiated in the 1970's when RA treatment was shown to disrupt anchorage-dependent growth in a few different cell lines (Lehmann et al. 1991). Recently, it has been shown that many carcinogenic cell types are missing retinoic acid receptors. Because retinoic acid seems to induce apoptosis, an accumulation of receptor deficient cells could be unresponsive to normal retinoic acid levels and therefore not undergo normal cellular death required for optimal health of the organism (Liu et al. 1996). In the nucleus, the RARs mediate the effects of RA on gene expression. The RARs are members of a large family of liganddependent transcription factors that include steroid, thyroid hormone, and vitamin D receptors (Bischoff et al. 1998). Numerous synthetic retinoids with receptor selective activities have been characterized. RARs have functional domains for RA and DNA binding, dimerization with other factors, and transcriptional activation. The DNA binding domain contains two zinc finger motifs. RARs interact with cognate response elements in the promoters of many genes. RARs bind DNA as heterodimers with retinoid X receptors 
(RXRs). RXRs bind 9-cis RA and possess homology to other members of the superfamily (Mangelsdorf et al. 1995)

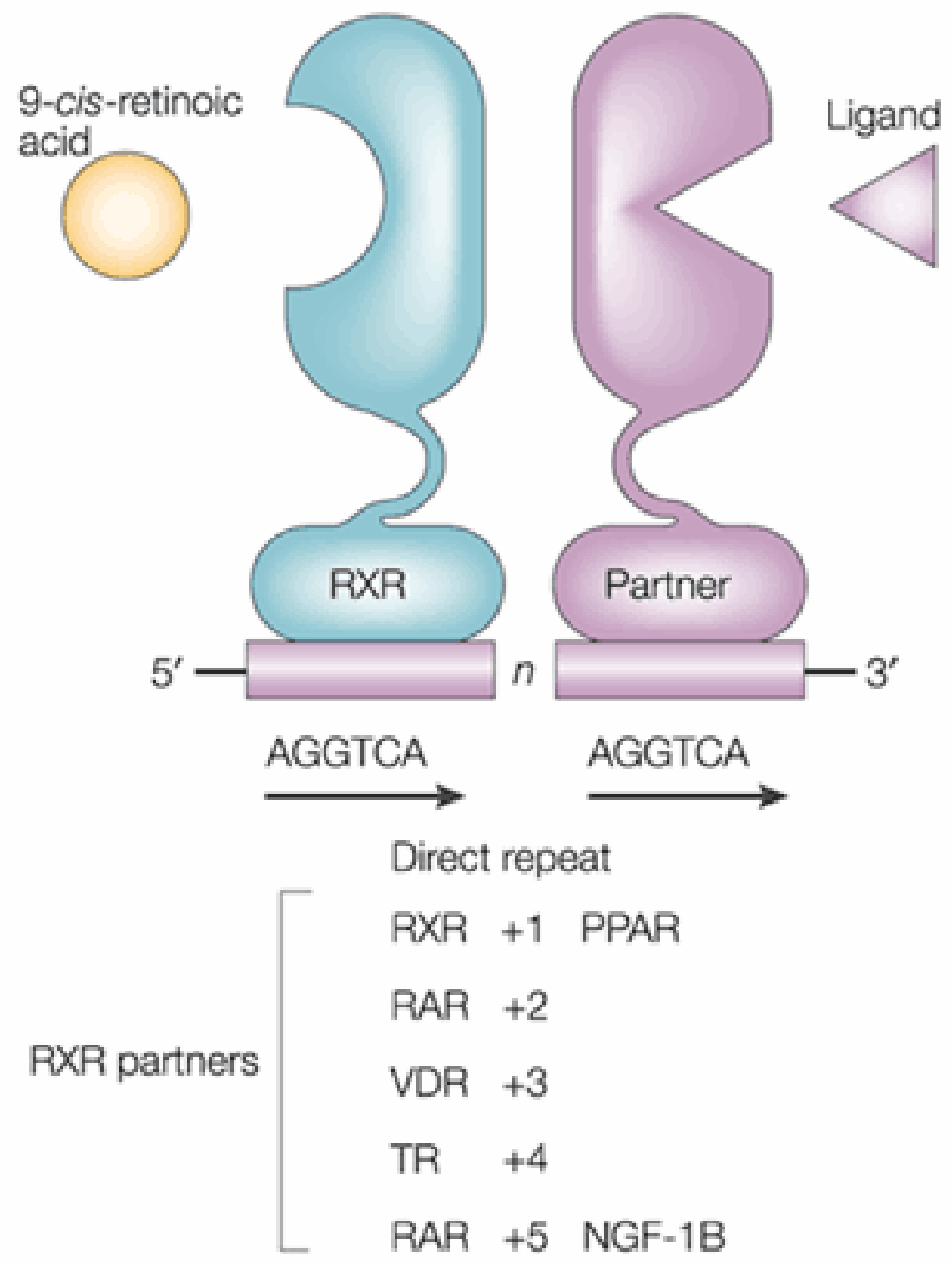

Figure 2.2.1. RXR binding partners

RARs have 6 domains named A-F. Domains A and B appear to be ligand independent transcription domains. Domain C is the DNA-binding domain, and D is a things domain specific for nuclear translocation and/or co-repression. Domain E seems to 
be for both dimerization and ligand binding. The $\mathrm{F}$ region is unknown to date (Sommer et al. 2002). When examining the role of RAR and its own genetic transcription, there appears to be a promoter problem in tumoregenic cells (Sun et al. 1997). There are three genes coding for RAR, but the problematic gene is RAR-beta. The gene has two promoters, one of which (P2) is highly down regulated. The transcription of this gene is controlled by a RARE, and thus RAR. It is a unique feedback mechanism which becomes disrupted in mammary carcinoma cells (Sommer et al. 2002).

Acyclo-retinoic acid was investigated for its possible role in activating the retinoic acid response element and slowing proliferation of immortal human mammary carcinoma cells (MCF-7) cells in culture. This retinoid is structurally and functionally similar to Lycopene (Leblanc et al. 1995). The result of the study showed a 100-fold decrease in RARE activity when compared to retinoic acid alone. Lycopene apparently does not show a direct affect on MCF-7 breast cancer cells, and does not act in place of retinoic acid (Ben-dor et al. 2002). MCF-7 cells treated with lycopene did not undergo apoptosis; however, they did show reduced activation of AP-1 transcription factor, IGF-1 receptor signaling, and cell cycle progression. These results indicate an inteference in cell cycle pathways by lycopene, which could be the reason for it's prescribed affect of reducing cancer risk (Ben-dor et al. 2002).

\subsection{Fatty Acids and Breast Cancer}

In 1982 the National Academy of Sciences suggested that breast cancer was related to consumption of a high fat diet (Kushi et al. 2002). Studies now show that it is also the type of fat consumed, not just the amount of fat contributing to the rise in breast 
cancer incidence. For example, Indian women have a high incidence of breast cancer in spite of a diet rich with fruits and vegetables (Kushi et al. 2002). In India, most foods are prepared with n-6 polyunsaturated rich vegetable oils (Kachhap et al. 1999). Case-control studies in Greece, Spain, and Italy have shown that consumption of olive oils (monounsaturated fat) reduce the incidence of breast cancer (Kushi et al. 2002). This protective effect may be due in part to its phenolic compounds that offer protection of lipids from oxidation (Gerber 1997). Another example of a specific fatty acid is Conjugated linoleic acid (CLA). This fatty acid is found in meat and dairy products. It can inhibit carcinogenic rat mammary tumor formation (Durgam 1997). The final lipid of interest is the omega-3 fatty acid. This fatty acid is considered anti-inflammatory, and has protective properties against breast cancer (Chajès et al. 1995).

Although not all experts agree, women who consume foods rich in omega-3 fatty acids routinely and over long periods of time are less likely to develop breast cancer then those that consume them sparsely (Wayne et al. 2004). Breast cancer mortality also seems significantly less for those who consume large quantities of omega-3 fatty acids. This is particularly true among women who substitute fish for meat in their diet. The balance between omega- 3 and omega- 6 fatty acids suggests an important role in the development and growth of breast cancer (Simopoulos 2002). Further research is still needed to understand the affect that omega-3 fatty acids may have on the prevention or treatment of breast cancer. Researchers speculate that omega-3 fatty acids may be more effective in combination with other nutrients (vitamin $\mathrm{E}$, vitamin $\mathrm{C}$, beta-carotene) in the treatment and/or prevention of breast cancer (Rose et al. 1999).

Studies on the effects of dietary fat on breast cancer have been carried out using several rodent experimental models. They consistently show that mice and rats are less 
likely to develop mammary tumors when they are fed low-fat as compared to high-fat diets (Cohen et al. 1986). Experimental evidence shows that dietary fat exerts its effect most commonly during the promotion phase of developing mammary tumors. However, the type of fatty acid is paramount in relation to breast cancer. For example, a diet providing a high proportion of n-6 polyunsaturated fatty acids (PUFA) greatly enhances tumor promotion (Simopoulos 2002). In contrast, diets high in linolenic acid found in fish oil inhibited the progression of mammary carcinogenesis (Rose et al. 1999). Studies on the influence of diets rich in monosaturated fatty acids such as olive oil, are inconclusive but at this time there are several results which give them a protective antitumor effect. More recently, it has been described that conjugated linoleic acid has also inhibitory effects on breast cancer (Durgam 1997).

The precise molecular mechanisms by which dietary fat might influence cancer development are potentially numerous as dietary fatty acids can modulate gene expression resulting in changes in metabolism, cell differentiation, and proliferation. Further, the cellular response to fat depends on the type of fatty acids, cell-specific metabolism and cell-specific transcription factors and nuclear receptors. The effects of dietary fat on tumor development may be indirect as a modulation of hormonal or growth factor mediated pathways. In addition, the oxidative stress due to generation of reactive oxygen species from fatty acids may contribute to the promotional effect of dietary fat by lipid peroxidation and damage of DNA and protein. Further, the metabolism of dietary fatty acids via the cyclooxygenase or lipoxygenase pathways may alter gene expression through the regulation of $\mathrm{G}$ proteins involved in signal transduction cascades that target the nuclear receptors.

\subsection{Fatty Acids}


Dietary fats, more specifically, fatty acids have become increasingly scrutinized over the last few decades. At the center of this scrutiny are the omega 3 and omega 6 fatty acids, with saturated and trans fatty acids following close behind. Omega 3 (GLA, DHA) fatty acids possess anti-inflammatory, antiarrhythmic, and antithrombotic properties. Omega 6 fatty acids (Linoleic) are proinflammatory and prothrombotic (Thoennes et al. 1999). Saturated fats and trans fats have been shown to increase LDLs, and subsequently have lead to an American population plagued by high cholesterol and heart disease (Kushi et al. 2002). Some scientists would argue that people simply eat a poor ratio of these different fats. Americans have a high ratio of omega- 6 fatty acids to omega-3 fatty acids in their diets. Simopoulos suggests that humans evolved with a ratio close to one, and the distance from that ratio of the western diet is a link to increased levels of mortality and morbidity (2002). The deviation from the evolutionary ratio seems to be a historical indicator for fatalities resulting from cardiovascular disease and cancer (Simopoulos 2002).

Fatty acids are an integral part of every physiological system in the human body. They are responsible for absorption of many essential nutrients such as vitamins A, D, and $\mathrm{K}$. When examining fatty acids it is important to differentiate between dietary fatty acids and fatty acids actively involved in metabolic processes. Dietary fatty acids are typically defined by the food one eats. For example, mono-unsaturated fats originate from olives, saturated fats originate from animals, omega-3 fats originate from fish, and of course trans fats are a product of partial hydrogenation. Fats are commonly defined metabolically. For example, the omega-3 fatty acid alpha linolenic acid (ALA) is a precursor to eicosopentaenoic acid (EPA), which in turn is a precursor for 
docosahexaenoic acid (DHA). Linoleic acid (LA), an omega-6 fatty acid, is the metabolic precursor to arachidonic acid (AA) (Rose et al. 1999). These fats are known as essential fatty acids (EFA), as the body does not synthesize them. Essential fatty acids belong to the class of fatty acids called polyunsaturated fatty acids (PUFAs). They have many functions among which are, stimulate hair and skin growth, maintain bone health, regulate metabolism, and maintain the capability to reproduce (Kachhap et al. 2000). They serve in forming body structures, maintaining immune system function, protecting vision, creating cell membranes, and producing eicosanoids (Thoennes et al. 1999). Eicosanoids, which include prostaglandins, are regulators of temperature, immune response, blood clotting, blood pressure, and inflammatory response.

\subsubsection{Omega 3 Fatty Acids}

Omega 3 fatty acids have been directly linked to the health of a human being. The omega-3 fatty acids are effective in the treatment of cardiovascular disease, arthritic disorders, and diabetes mellitus (Rose et al. 1999). The dietary omega-3 fatty acids that may impact cancer include eicosapentaenoic acid (EPA) and docosahexanoic acid (DHA). These fats are found primarily in fatty fish such as salmon and tuna (Rose et al. 1999).). Another rich source of omega-3 fatty acids is seaweed, and is the only true plant source of EPA and DHA. The other omega-3 fatty acid is ALA and is readily found in flaxseed and dark leafy green vegetables. The body can enzymatically convert ALA to EPA. All three fatty acids are paramount to human health (Simopoulos 2002).

Approximately $1 \mathrm{~g}$ of EPA acid DHA consumed per day orally is recommended for cardio protection. Higher dosages of omega-3 fatty acids are required to reduce 
elevated triglyceride levels ( 2 to $4 \mathrm{~g}$ per day) and to reduce the stiffness in the number of joints in patients with rheumatoid arthritis (at least $3 \mathrm{~g}$ per day)( Rose et al. 1999).). Small decreases in blood pressure can occur with higher dosages of omega 3 fatty acids (Rose et al. 1999).).

\subsubsection{Omega 6 Fatty Acids}

Omega 6 fatty acids are derived from a variety of sources. Most omega 6 fatty acids are consumed in the human diet, and are found in vegetable oils as linoleic acid. Linoleic acid is converted to gamma-linolenic acid (GLA), and then further broken down to arachidonic acid (AA). Arachidonic acid can also be consumed directly from meat. Gamma-linolenic acid can be part of a diet containing specific plant oils including: evening primrose oil (EPO), borage oil, and black currant seed oil (Kachhap et al. 2000).

Excess amounts of LA and AA are unhealthy because they can promote inflammation, which can potentially lead to heart disease and cancer (Reyes et al. 2004). In contrast, GLA seems to reduce inflammation (Cohen et al. 1986). When GLA is taken as a supplement, it is not converted to AA. Rather, it is converted to dihomogammalinolenic acid (DGLA). Dihomogamma-linolenic acid competes with AA and prevents the normal inflammatory effects that AA would have caused the body. Dihomogammalinolenic acid also becomes involved with prostaglandins, which reduce inflammation. Important dietary concerns are considered for this process to take place. Adequate amounts of magnesium, zinc, and vitamins B3, B6, and C help to promote the conversion of GLA to DGLA (Reyes et al. 2004). 


\subsubsection{Monounsaturated Fatty Acids}

Monounsaturated fatty acids have functionally specific roles in the human body. These fatty acids are an important source of energy for the body, and are also important constituents of cell membranes. Monounsaturated fatty acids regulate hormone response, nutrient uptake, and waste removal. They are also very important as oils of the skin (Gerber 1997).

Monounsaturated fatty acids (MUFAs) have a single double carbon bond found with a cis configuration. These fatty acids cannot closely associate with neighboring fatty acids due to this double bond and consequently act as a liquid oil at room temperature. Monounsaturated fatty acids can be synthesized in the body, and are normally completed by a double bond insertion between the ninth and tenth carbons of a saturated fatty acid. This reaction creates either oleic acid or palmitoleic acid, depending on the original saturated fat. The common fat, oleic acid, is created using stearic acid. Palmitoleic acid is created from a palmitic acid chain. Together, these two fatty acids can be found in a variety of foods. Oleic acid is present in almost all animal fats and vegetable oils. It is the most common fatty acid in olive oil, canola oil, and sunflower oil. Palmitoleic acid is found in coconut and palm oils (Gerber 1997).

\subsubsection{Conjugated Linoleic Acid}

Conjugated Linoleic Acid (CLA) has been shown to be a very effective treatment in preventing the proliferation of breast cancer cells in vitro (Maggiora et al. 2004). 
Conjugated Linoleic Acid is a mixture of positional and geometric isomers of linoleic acid. It is found in ruminant foods such as meat and dairy products $(0.6-5.6 \mathrm{mg} \mathrm{CLA} / \mathrm{g}$ fat), and has proven to be an effective inhibitor of carcinogenic rat mammary tumors (Durgam 1999). It is unique due to its presence in animal food sources, and its anticancer efficacy is expressed at concentrations close to human consumption levels.

CLA has been shown to increase metabolic rate, decrease body fat, increase lean muscle, lowers cholesterol and reduces insulin resistance. CLA is a slightly altered form of LA, an omega-6 fatty acid important to human health. Recently, it has been widely produced as a supplement which claims cancer prevention. It remains to be extensively tested and/or completely understood (Chujo et al. 2003).

\subsubsection{Trans Fatty Acids}

On November 12, 1999, the Food and Drug Administration announced that it would include the trans fatty acid content of foods on standard food labels. Metabolic studies reveal that trans fats have adverse effects on blood lipid levels increasing LDL cholesterol while decreasing HDL cholesterol. This combined effect on the ratio of LDL to HDL cholesterol is double that of saturated fatty acids (Mensink 2008). Trans fats have also been associated with an increased risk of coronary heart disease in epidemiologic studies (Willett 2007).

Unsaturated fatty acids are naturally found in a cis configuration. Trans fatty acids have the hydrogen atoms on opposite sides. These trans double bonds can occur naturally in ruminants, and will show low levels in many meat and dairy products. Trans unsaturated fatty acids are produced artificially by introducing heat to liquid vegetable 
oils in the presence of metal catalysts and hydrogen (Katan 2009).

\subsection{Vitamin A}

Vitamin A is a generic term for a large number of related compounds. The alcohol form is named retinol, while the aldehyde is termed retinal. These are commonly referred to as pre-formed vitamin A. Retinoic acid is formed in the body from retinal and is actively involved in molecular processes. These three compounds as well as others similar in form and function are collectively known as retinoids. Another group of compounds known as carotenoids have been termed provitamin A. Beta-carotene is found in this category, and is found in a variety of sources in the environment (Prakash et al. 2000).

Vitamin A is found naturally and occurs in many forms from a variety of both plant and animal sources. Retinol, the free form, is not found in foods. Carotenoids are found specifically in plants. Leafy green, and brightly colored are the most significant sources of carotenoids (Prakash et al. 2000). Retinyl palmitate is the major source of retinol found in animals. It is a storage form which acts as a precursor for retinol. In those foods where retinol activity comes mainly from provitamin A carotenoids, the carotenoid content and the retinol activity equivalents are presented (Thurnham et al. 2003). The USDA food composition database provides the content of several different carotenoids, including lycopene, lutein and zeaxanthin.

Vitamin A exists as provitamin B carotene found in foods such as milk, eggs, and many fruits and vegetables. It is absorbed in the intestine and travels to the liver as a retinyl ester. It is stored in the liver, or its ester is cleaved and it travels through the body 
bound to retinol binding protein (RBP). Retinoic acid is transported bound to albumin. Once retinol enters the cell it binds to cellular retinol binding protein (CRBP) and from there can be oxidized into retinal and retinoic acid by retinaldehyde dehydrogenase (Lei 2003). It has been shown that genes induced by retinoic acid transcription factors control most of the targets involved in the metabolic activities of retinoids. It is a unique feedback system, which shows the dependency of the organism on these processes (Lei 2003).

Retinol from dietary sources (vitamin A) is metabolized intracellularly and results in its active versions: all-trans retinoic acid (tRA) and 9-cis retinoic acid (9-cis RA). Retinoid functions are exerted through their binding with their receptors. The receptors are termed retinoic acid receptors (RAR) and retinoic $\mathrm{x}$ receptors (RXR) (Ben-dor et al. 2002). The difference between the two is RARs have a high affinity for all-trans-retinoic acid, while the RXRs tend to bind with cis forms of retinoic acid. The receptors act as a dimer, and then (bound to their ligand) are imported into the nucleus as transcription factors where they bind to the retinoic acid responsive element (RARE) (Ben-dor et al. 2002). While RAR bound to trans-RA seems to have an antiproliferative effect on MCF-7 cells in culture, RXR does not show any effect on cell growth. Cis-RA and RXR have not been shown to result in the same level of cancer suppression as RAR and trans-RA (Liu et al. 1996). 
4-oxo-RA, 4-OH-RA, 5,8-epoxy-RA

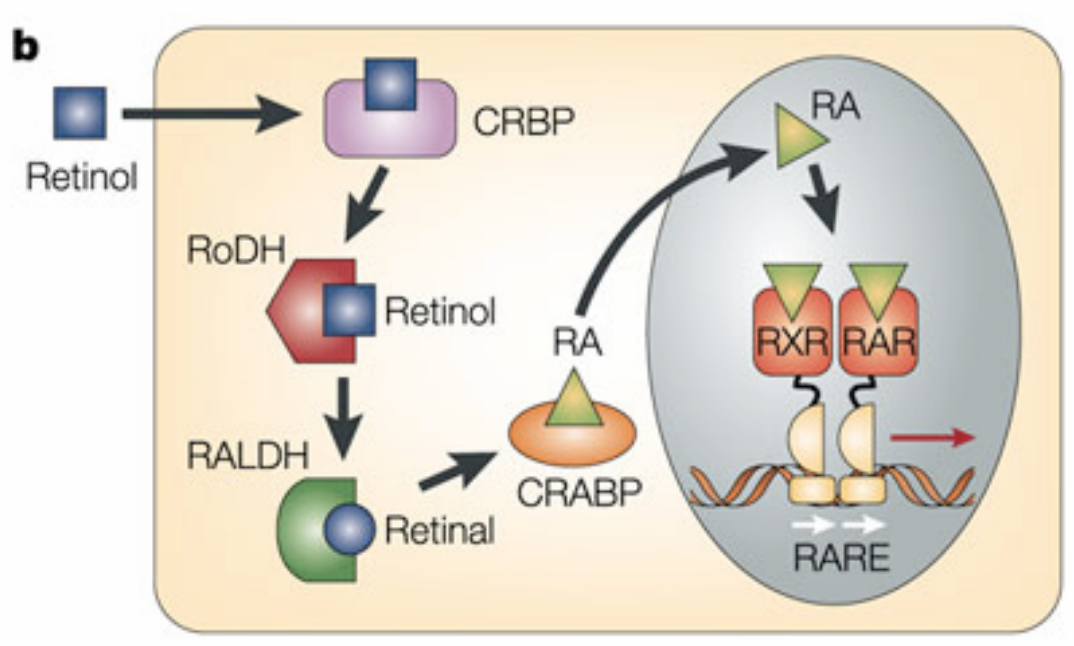

Figure 2.5.1 Retinol conversions (a) and binding sites (b) intracellularly

Vitamin A deficiency among children in developing nations is the leading preventable cause of blindness (Semba et al. 2004). The most common diseases associated directly with vitamin A deficiency is of the eye. Night blindness from impaired 11- cis retinal production is common (Semba et al. 2004). Also a condition of the conjunctiva called Bitot's spots can be observed during a deficiency (Semba et al. 2004). The most severe form of vitamin A deficiency in the eyes is known as xeropthalmia. This condition leads to dry eyes, corneal ulcers, scarring, and eventually total blindness (Semba et al. 2004). Vitamin A deficiency is also considered an acquired immunodeficiency disease as described by Semba. Inadequate vitamin A intake has also 
been shown to lead to increased incidence of infectious disease. Interestingly, vitamin A supplementation in developing countries decreases deaths in children from diarrhea and measles (Thurnham et al. 2003).

The RDA for vitamin A was revised by the Food and Nutrition Board (FNB) of the Institute of Medicine in 2001. Vitamin A has an RDA of 900mcg/day for men and $700 \mathrm{mcg} /$ day for women. The latest RDA is based on the amount needed to ensure an adequate store of vitamin $\mathrm{A}$ in the body. This store is a sufficient amount to support normal vision, immune function, maturation, growth, and gene expression (Semba et al. 2004).

Vitamin A is an integral part of the signal transduction required for vision. As light passes through the lens of the eye, it is received by the retina located at the rear of the eye. The light is then converted to a signal, which the brain translates into vision. At the epithelial surface of the retina, retinol is esterified to form a retinyl ester. These esters are then isomerized following hydrolysis and become 11-cis retinol. Following oxidation this compound becomes11-cis retinal. The importance of 11-cis retinal is its ability to bind to opsin and form rhodopsin. Rhodopsin is found on rod cells of the eye, which are important in night vision. 11-cis retinal isomerizes to all-trans retinal, which results in the signal cascade responsible for vision.

Vitamin A is necessary for the normal and healthy activities of the human immune system. Better known as retinol, vitamin A and its metabolites are required to maintain the correct function of the mucosal cells (epithelial cells) found in the urinary, digestive, and reproductive tracts. Retinol and retinoic acid (RA) have an integral role in the development and differentiation of lymphocytes, and AtRA is required by T-lymphocytes 
for proper regulation of the immune system.

Both vitamin A excess and deficiency are known to cause birth defects. Retinol and retinoic acid (RA) are essential for embryonic development (Christian 2003). During fetal development, RA functions in limb development and formation of the heart, eyes, and ears (Pavia 1999). Additionally, RA has been found to regulate expression of the gene for growth hormone (Christian 2003)

Red blood cells, like all blood cells, are derived from precursor cells called stem cells. These stem cells are dependent on retinoids for normal differentiation into red blood cells. Additionally, vitamin A appears to facilitate the mobilization of iron from storage sites to the developing red blood cell for incorporation into hemoglobin, the oxygen carrier in red blood cells (Christian 2003).

Delivery of RA to its receptor within the cell has been a topic of interest recently, and it has yet to be fully understood. The current theory on RA delivery is a combination of passive diffusion and the action of a carrier protein. Cellular retinoic acid binding protein II (CRABPII) has been uncovered as that carrier protein. Upon binding to its ligand (RA) it undergoes a massive conformational change in the cytosol near the nucleus. The change causes a rapid recruitment into the nucleus where RA is delivered to its receptor RAR or RXR. The collision-mediated process leaves the binding protein empty and is then immediately exported from the nucleus back to the cytosol where it awaits another ligand. Recent research has concluded that the CRABPII is a necessary and exciting pathway by which retinoic acid induces growth arrest in mammary carcinoma cells (Budhu et al. 2002). Over expression of CRABPII in MCF-7 cells showed a significant decrease in cell proliferation, while silencing the protein allowed the 
cells to proliferate as if there was no RA in the treatment.

\subsection{Nuclear Hormone Receptors}

Nuclear hormone receptors may be responsible for the combines effect of Vitamin A and Fatty Acid on carcinogenesis. More specifically, the peroxisome proliferatoractivated receptors (PPARs) are the hypothesized to play a role in the decreased cell proliferation. (Moller et al. 2003). The PPARs are ligand-activated transcription factors

of the nuclear hormone receptor superfamily. They share a high degree of structural homology with all members of the superfamily, particularly in the DNA-binding domain and ligand- and cofactor-binding domain. Many cellular and systemic roles have been attributed to these receptors, reaching far beyond the stimulation of peroxisome proliferation in rodents after which they were initially named. Peroxisome proliferatoractivated receptors exhibit broad, isotype-specific tissue expression patterns. PPAR $\alpha$ is expressed at high levels in organs with significant catabolism of fatty acids. PPAR $\beta / \delta$ has the broadest expression pattern, and the levels of expression in certain tissues depend on the extent of cell proliferation and differentiation. PPAR $\gamma$ is expressed as two isoforms, of which PPAR 2 is found at high levels in the adipose tissues, whereas PPAR $\% 1$ has a broader expression pattern. 


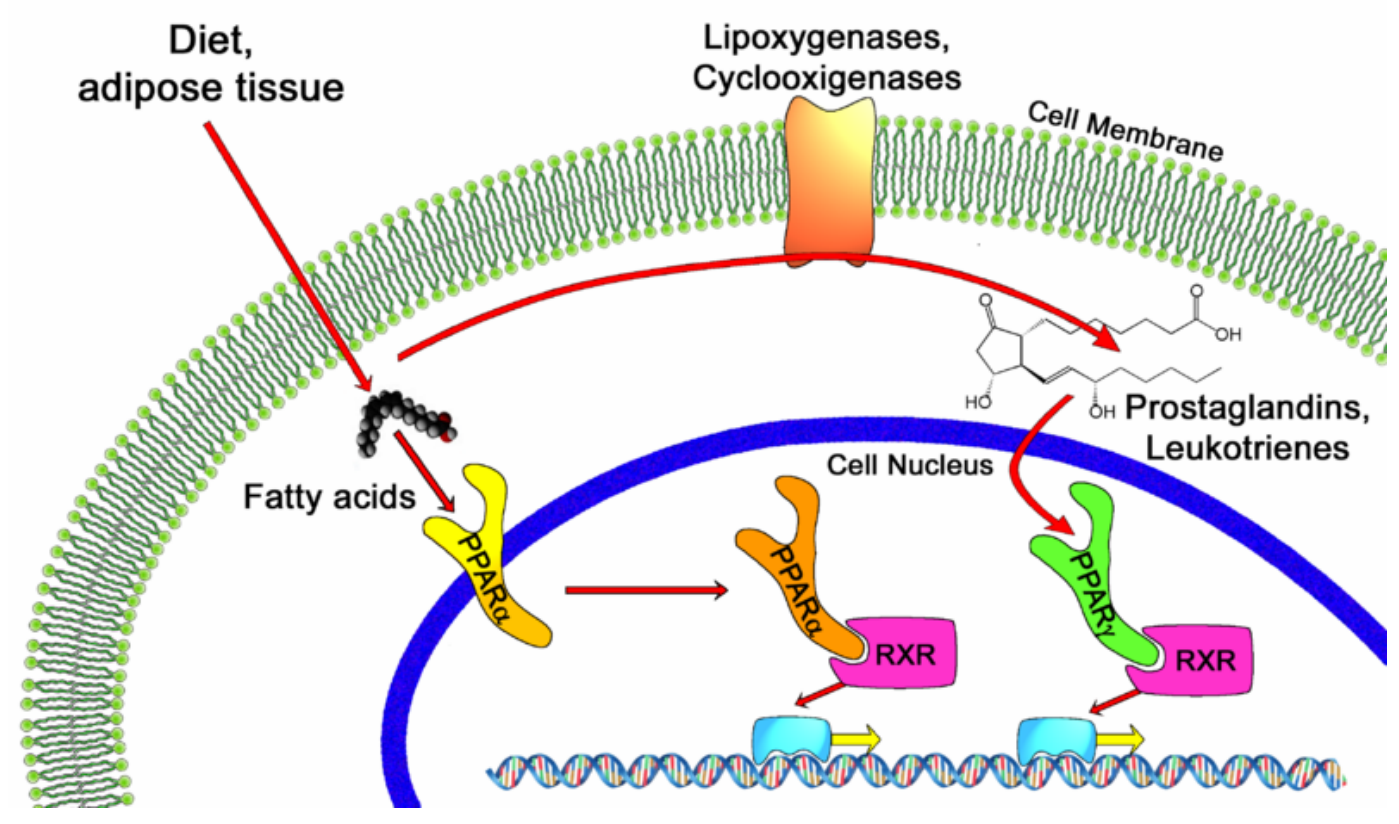

Figure 2.6.1: PPAR alpha and gamma pathways.

Transcriptional regulation by PPARs requires heterodimerization with the retinoid $\mathrm{X}$ receptor (RXR)( Vu-Dac et al. 1998). When activated by a ligand, the dimer modulates transcription via binding to a specific DNA sequence element called a peroxisome proliferator response element (PPRE) in the promoter region of target genes (Kersten et al., 1999). A wide variety of natural or synthetic compounds have been identified as PPAR ligands. Among the synthetic ligands, the lipid-lowering drugs, fibrates, and the insulin sensitizers, thiazolidinediones, are PPAR $\alpha$ and PPAR $\gamma$ agonists, respectively, which underscores the important role of PPARs as therapeutic anti-cancer targets (Staels et al., 1998). Transcriptional control by PPAR/RXR heterodimers also requires interaction with coregulator complexes (Kersten et al., 2001). Thus, selective action of PPARs in vivoresults from the interplay at a given time point between expression levels of each of the three PPAR and RXR isotypes, affinity for a specific promoter PPRE, and ligand and cofactor availabilities. 
Consistent with its distribution in tissues with high catabolic rates of fatty acids and high peroxisomal activity, the major role of PPARe is the regulation of energy homeostasis (Lefebvre et al. 2006). In the liver especially, PPAR $\alpha$ activates fatty acid catabolism, stimulates gluconeogenesis and ketone body synthesis, and is involved in the control of lipoprotein assembly (Staels et al. 1995). PPARa also stimulates heme synthesis and cholesterol catabolism (Staels et al. 1995). Furthermore, it attenuates inflammatory responses and participates in the control of amino acid metabolism and urea synthesis (Devchand et al. 1999). Increased fatty acid oxidation by activated PPAR $\alpha$ lowers circulating triglyceride levels, liver and muscle steatosis, and reduces adiposity, which improves insulin sensitivity (Guerre-Millo et al. 2000; Chou et al. 2002). Not surprisingly, fibrate drugs such as gemfibrozil, clofibrate, and fenofibrate that are widely used to treat hypertriglyceridemia are activators of PPAR $\alpha$. In addition, PPAR $\alpha$ agonists have demonstrated significant anti-inflammatory activities that seem to play arole in their protective actions within the cardiovascular system (Berger et al. 2005).

\subsection{Nutrient Delivery Systems}

The delivery of AtRA has not been easily performed to date. The goal of establishing therapeutic levels of AtRA in tissue has also met some barriers. These barriers include issues of compound stability, and also tissue safety.

While beneficial as an anti-cancer agent, the use of AtRA is not without complications. AtRA is a water insoluble, toxic agent with limited bioavailability (Freemantle et al. 2003). Pharmacological levels can cause retinoic acid syndrome and neurotoxicity, particularly in children (Takitani et al. 2006). In addition, drug resistance has been reported in cases of sustained ATRA treatment requiring the use of additional 
cytotoxic chemotherapy (Freemantle et al. 2003). Although liposomal formulations were developed a number of years ago in an effort to address these issues, they have not progressed past the clinical trial stage (Freemantle et al. 2003). Despite this, the potential benefits of associating ATRA with a lipid-based carrier are many. Not only do lipid-drug formulations address solubility issues, they also decrease toxicity and potentially avoid triggering ATRA resistance, thereby minimizing the need for additional chemotherapy (Freemantle et al. 2003).

In conjunction with this study, our research team was involved in exploring possible applications of the above named Liposomes. Liposomal delivery offers many specific stability advantages of AtRA, and we were able to produce results in vitro supporting the possibility of further usage. The application model stemmed from using dairy based fatty acids to produce liposomes that delivered AtRA. Appendix D has the full results. Liposome use is a viable option for future delivery of AtRA and could be engineered with specific fatty acids as well. The search for a viable delivery option from liposomes is currently underway, and should yield realistic applications in the future to treat carcinomas.

\section{Chapter 3.0}




\section{MATERIALS AND METHODS}

\subsection{Materials}

MCF-7 cells were obtained from the American Type Institute. AtRA was obtained from Sigma Aldrich (St. Louis MO). Fatty Acids and other chemicals were obtained from Fisher Scientific (Pittsburgh, PA).

\subsection{Cell Experiments}

MCF-7 cells were cultured at $37^{\circ} \mathrm{C}, 5 \% \mathrm{CO} 2$, in Dulbecco's Modified Eagle Media (DMEM) containing 10\% fetal bovine serum (FBS) and 1\% antibiotic. FBS and the antibiotic (50:50, penicillin and streptomycin) added to the media, sterile filtered using a bottle top vacuum filter. $75 \mathrm{~cm}^{\wedge} 2$ cell culture flasks were carefully monitored for confluence and were passed upon a $75 \%$ confluency. Cells were grown consistently in 20 $\mathrm{ml}$ of media until confluent. MCF-7 cells did not require a media change to ensure confluency. The cells were considered "stock" cells which were transferred to growth plates for growth assays.

\subsection{Cell Counting}

Cells collected via trypsin in a $15 \mathrm{ml}$ Falcon tube. The tube spun at $1800 \mathrm{RPM}$ for 5 minutes in a centrifuge to collect pellet. The cells were resuspended by light vortexing in $1 \mathrm{ml}$ of fresh media. Sample (5 ul) of cells was counted on a hemacytometer (Figure 3.1) to determine amount of cells in the $1 \mathrm{ml}$. 48 well plates seeded for cell proliferation assays, and each well contained 5000 cells as determined by a hemacytometer. Cells adhered for 24 hours before treatment. 


\subsection{Cell Treatments}

AtRA treatments began with a growth curve. Cells seeded in 48 well growth plates for 24 hours until confluent. Media removed, new media (void of FBS) containing treatments added. Stepwise increases in AtRA (in DMSO) concentration (.5 - $10 \mathrm{uM})$ were used, and cells analyzed after both 24 and 48-hour growth periods. 1 uM AtRA chosen to pair with fatty acid treatments. AtRA extinction treatments also examined at time zero, vs daily treatments over 72 hours.

Fatty Acids (Linolenic, Linoleic, and Palmitic Acid) were used to treat the MCF-7 cells over 24 and 48 hours. Later, $1 \mathrm{uM}$ of AtRA was combined with $2.5 \mathrm{uM}$ of each fatty acid. Growth carefully monitored over 72 hours with identical wells receiving either a single treatment at time zero, or receiving multiple treatments ( 1 every 24 hours). DMSO was controlled at $1 \%$ by volume. Each designated time period ended with media removal from each plate and placed in $\mathrm{a}-20$ degree $\mathrm{C}$ freezer for later analysis.

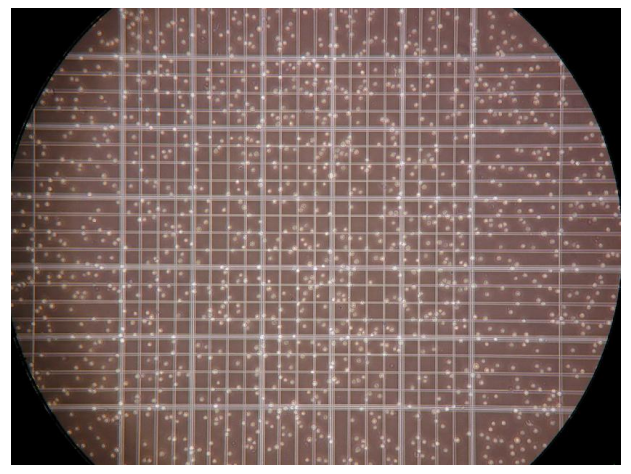

Figure 3.1: View of hemacytometer grid (10x) and cells. Cells are counted in squares and determine the amount of cells in solution following calculation.

\subsection{Cell proliferation assay}

Cell proliferation measured by fluorescence using the Cyquant Cell Proliferation Assay Kit (Invitrogen CO. Carlsbad, CA). Each plate removed from freezer and thawed. 
Nano-pure water $(19 \mathrm{ml})$, lysis buffer $(1 \mathrm{ml})$, and a florescent dye (50 ul) combined and added to each well in $200 \mathrm{uL}$ aliquots. 30 minutes of incubation was required before the first reading and emission was stable for up to 60 minutes.

\subsection{Cell proliferation quantification}

A Typhoon Variable Mode Imager (General Electric Health Care) read the florescent stained cellular nucleic acids through a flourecein filter at $520 \mathrm{~nm}$ following a green laser excitation of the dye. Following the scan, the resulting image was manipulated and evaluated by the Imagequant TL software (Amersham Biosciences). Each well evaluated by color absorption then measured against control wells to give cell proliferation comparisons.

\section{Chapter 4}

\section{RESULTS}

MCF-7 cell growth was limited by media containing AtRA. A growth curve analysis of MCF-7 cells in the presence of AtRA in varying concentrations was produced 
to investigate its efficacy in decreasing cell proliferation.. Figure 4.1 shows the decrease in growth with each concentration as compared to media not supplemented with AtRA (control). 5uM AtRA concentration showed the largest decrease, the $1 \mathrm{uM}$ concentration was chosen for further analysis. $1 \mathrm{uM}$ decreased cell growth by $32.9 \%$ after 24 hours.

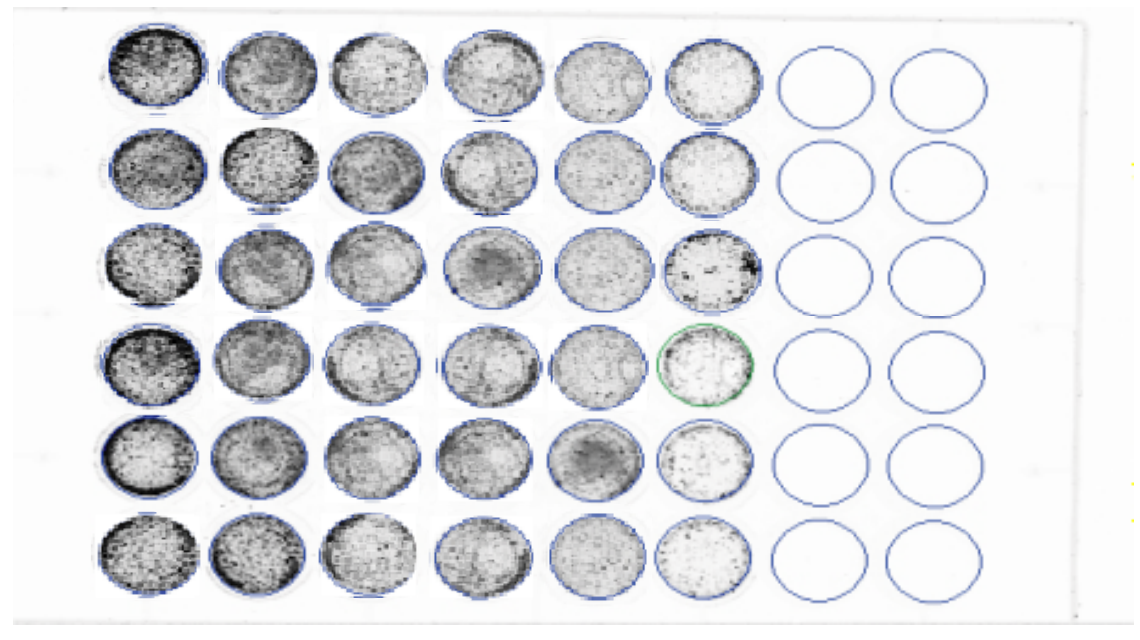

Figure 4.1: Molecular Probes Cyquant Kit: 5000 cells were seeded per well and allowed to adhere overnight before treatments were given 24 hours later in serum free media. Proliferation was significantly altered with the use of ATRA. Columns C-F are $0.5 \mathrm{uM}-$ 5.0uM AtRA in media respectively. (Images produced on a Typhoon Scanner, and manipulated with Imagequant software. (Image is of actual size) 


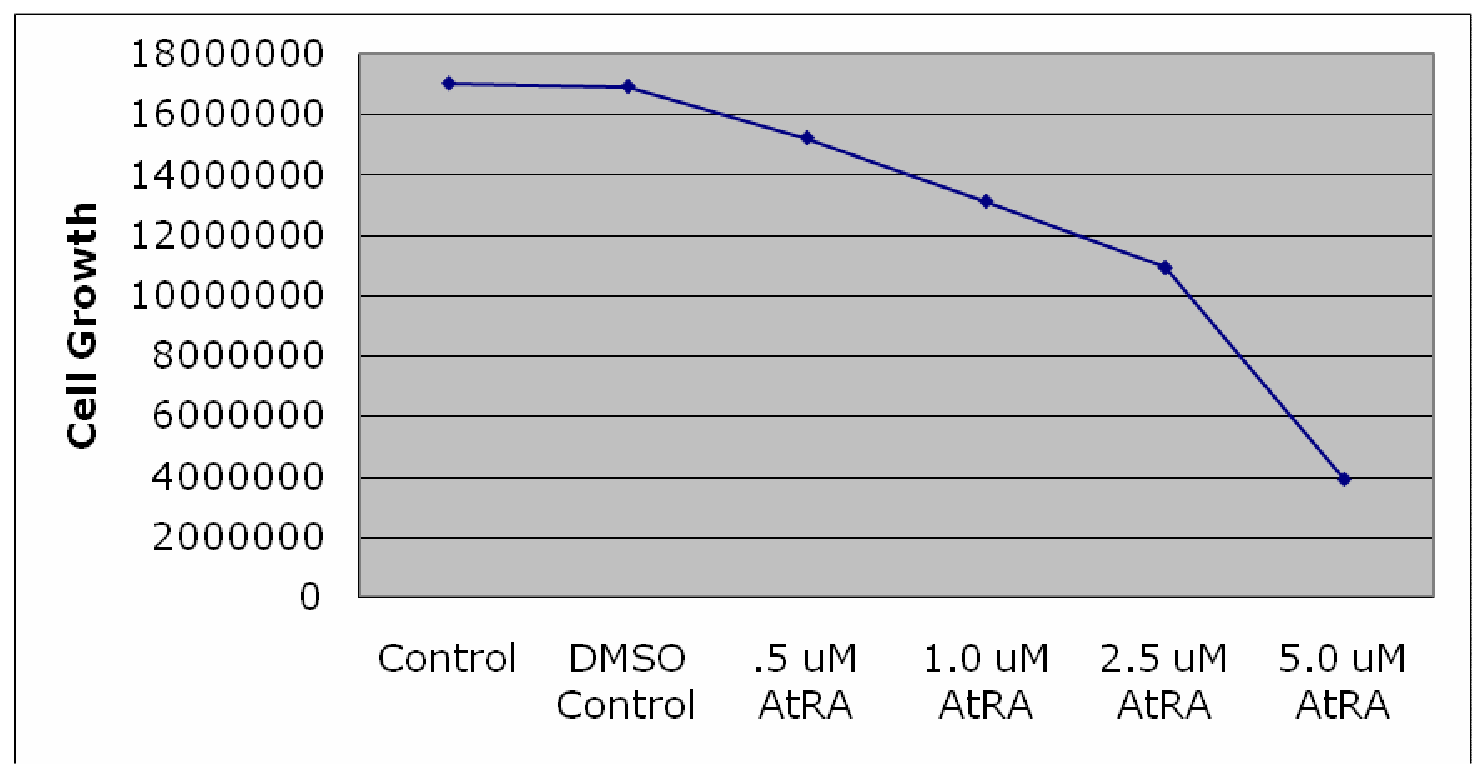

Figure 4.2: Cell Proliferation Assay. Standard curve for cell growth under varying amounts of AtRA delivered in vitro. Ideal treatment was found to be $1 \mathrm{uM}$ which was not greater than $50 \%$ cell growth reduction. (Numbers taken from Figure 1 to produce graph)

Linolenic acid decreased MCF-7 cell proliferation in vitro. Linolenic acid delivered to MCF-7 cells via media over 72 hours decreased cell growth by $26.5 \%$. Linoleic acid was used as a control to investigate fatty acids delivered in media. Linoleic did show a slight decrease in cell proliferation (10.1\%), it was not consistent and was not considered significant.

AtRA combined with Linolenic acid decreased MCF-7 cell proliferation greater than AtRA alone. Over 72 hours of refeeding treatments, 1 uM AtRA combined with 2.5 uM Linolenic acid decreased cell proliferation by $73.4 \%$. This was $49.7 \%$ less then AtRA alone, and $87.4 \%$ less than Linolenic acid alone. Figure 4.3 shows the percent growth of the control. 


\section{MCF-7 Cell Growth (72hr)}

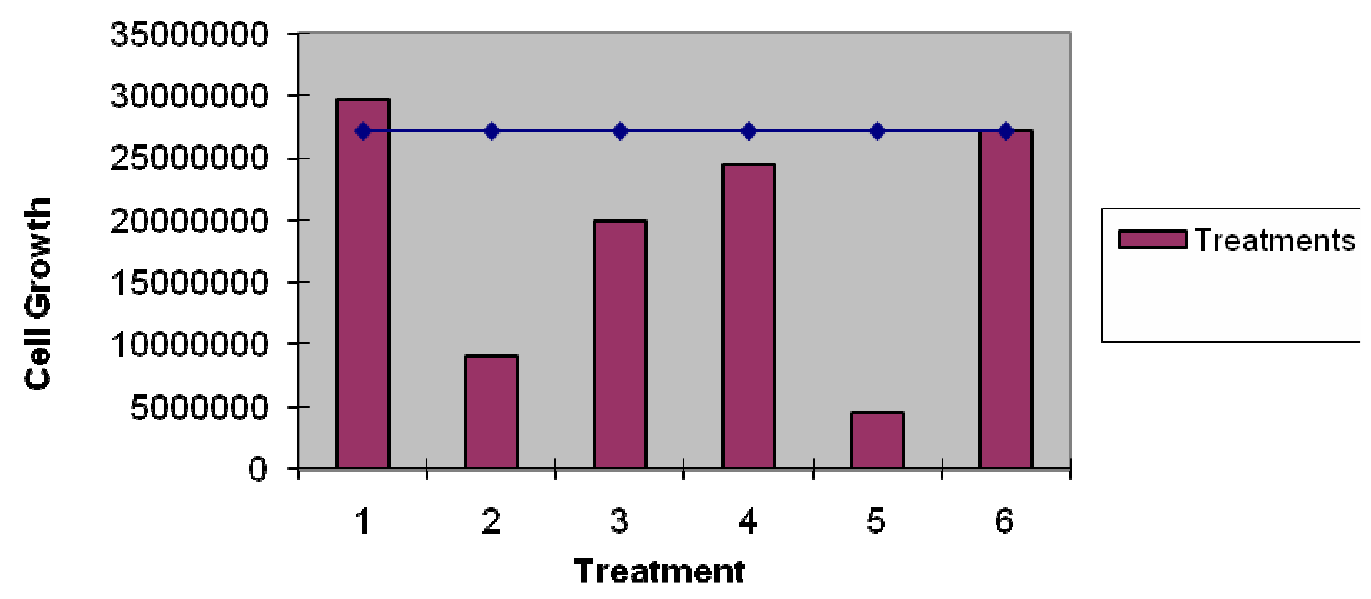

Figure 4.3: Cell Proliferation Assay: Data presented as percent of control. AtRA (1uM) along with AtRA + Linolenic acid produced significant growth differences over 72 hours. The combined affect was $49.7 \%$ greater then AtRA alone, and was significantly different.

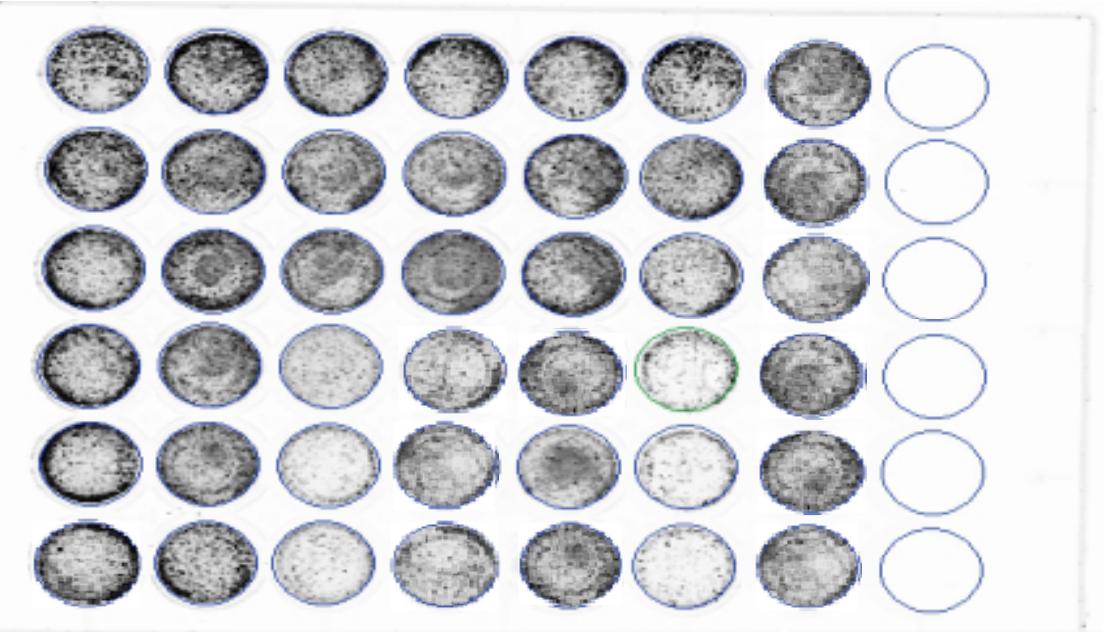

Figure 4.4: Molecular Probes Cyquant Kit: 5000 cells were seeded per well and allowed to adhere overnight before treatments were given 24 hours later in serum free media.

Proliferation was significantly altered with the use of ATRA $(1 \mathrm{uM})$ and the combination of ATRA (1uM) with Linolenic Acid ( $2.5 \mathrm{uM})$. Treatments were only affective with daily dosage as opposed to a single dosage on day 1 . Columns $\mathrm{C}$ and $\mathrm{F}$ illustrate this difference. (Images produced on a Typhoon Scanner, and manipulated with Imagequant software. (Image is of actual size)

\subsection{AtRA and Linolenic Acid Combined Treatment Results}


The combined affect of treatments was only seen after 72 hours of re-feeding, and cells given only 1 treatment on day 1 did not show the same results. Figure 4.5 shows the relationship of single treatments vs. re-feeding daily treatments.

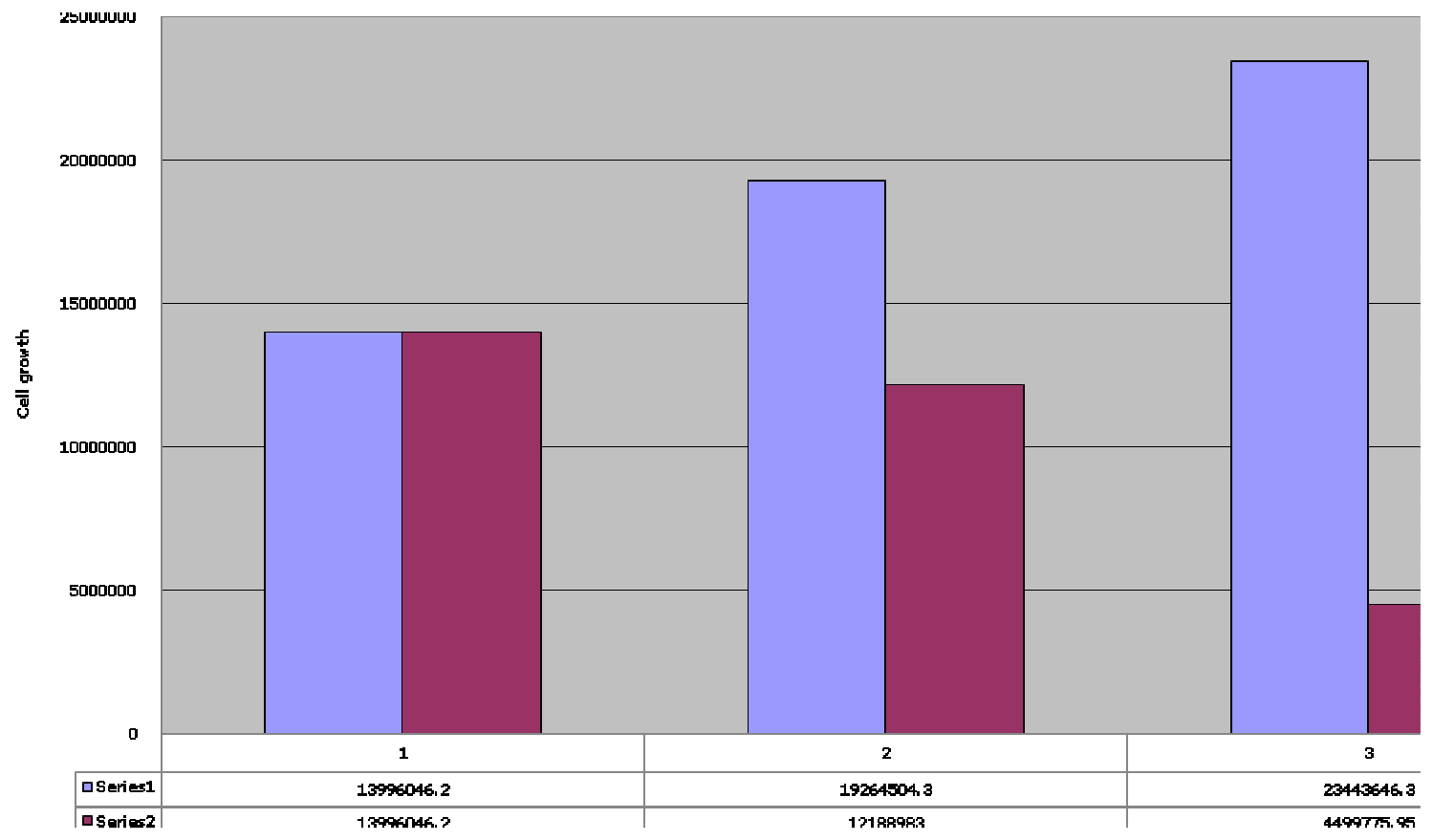

Figure 4.5: Series 1 is cell proliferation following single treatment at time zero, vs series 2 which is treatments every 24 hours.

\subsection{Statistical Analysis}

Statistical significance $(\mathrm{p}<.05)$ was found when comparing AtRA+ linolenic acid, and linoleic acid treatments with an ANOVA. Daily AtRA feeding was statistically different $(\mathrm{p}<.05)$ from all of the other treatments accept AtRA combined with Linolenic Acid, and the Linolenic acid treatment alone. AtRA combined with Linoleic acid was significantly different $(\mathrm{p}<.05)$ from AtRA + linolenic Acid, and linolenic acid alone. Daily feedings were all statistically different $(\mathrm{p}<.05)$ from single feedings (at time zero) except for single AtRA feedings on day 1. 
Chapter 5 


\section{DISCUSSION}

All-trans retinoic acid has historically been evaluated and applied in chemoprevention of epithelial cancers. Linolenic acid has also been explored for possible application in chemoprevention. Here, we have explored the synergism of these two compounds through an in-vitro application in a specific cell line. We have also hypothesized the connection with these compounds to be found on the nuclear level in the form of transcription factor specific receptors: Perxisome-proliferator activated receptor gamma (PpARy), and Retinoic Acid receptor (RXR). MCF-7 cells are an appropriate choice when exploring RXR and PPAR do to their previous use in these applications. Other epithelial cell lines do not produce the same quantity of receptors and have not shown the same promising results. Unique expression patterns of PPAR $\gamma$ relative to RXR in certain cell lines led us to hypothesize that applying a known ligand for each receptor would significantly affect the progression of MCF-7 cell growth in vitro. Our hypothesis was supported by current research where up-regulation of the PPARE was noted with increased ligand activity of RXR (Nicol et al. 2004).

A growing body of evidence indicates PPAR $\gamma$ is involved in both breast cancer development and progression. PPAR $\gamma(+/-)$ mice had almost three-fold increased incidence of mammary adenocarcinomas and decreased survival rate when compared to PPAR $\gamma(+/+)$ litermates (Nicol et al. 2004). Several reports have demonstrated that treating animals with PPAR $\gamma$ ligands prior to chemical induction of mammary tumors is protective against tumor development (Nicol et al. 2004). It appears that expression and transactivation of PPAR $\gamma$ is protective against breast tumor formation particularly when 
activated by PPAR $\gamma$ ligands. Our data demonstrates that a particular ligand (Linolenic Acid) seems effective at transactivating PPAR $\gamma$ in normal mammary epithelia.

Once a breast tumor has formed, PPAR $\gamma$ appears to have multiple effects. One study observed that distinct PPAR $\gamma$ ligands induce apoptosis (Nicol et al. 2004). Conversely, a recent report by Saez et al. (2004) found that when mice expressing a constitutively active form of PPAR $\gamma$ in the mammary gland were crossed with mice prone to mammary gland cancer, bigenic animals develop tumors that express higher levels of markers of malignancy. The authors conclude that once an initiating event takes place, increased PPAR $\gamma$ signaling serves as a tumor promoter in the mammary gland of these experimental animals. Collectively, these data suggest that the physiological consequence of PPAR $\gamma$ activation is dependent on many factors including the stage of development of the specific breast cancer cell.

Our demonstration that an individual PPAR $\gamma$ ligand (Linolenic Acid) showed promising results follows the trend previously demonstrated in literature. We also demonstrated the use of a RXR ligand to slow the progression of MCF-7 cell growth in vitro. Interestingly, further decrease in progression was observed with the co-treatment of both ligands. The heterodimeric relationship of RXR and PPAR $\gamma$ has been shown to have its own response element PPARE which was shown to be up-regulated by ligands of either receptor independent of eachother. We have shown here that there is also promise of increased transcription through increased availability of both ligands.

It can be concluded that individual breast cancer cell types are likely to respond to PPAR $\gamma$ ligands and RXR ligands in unique physiological ways and our data suggests that, 
in part, variant cellular responses are the result of selective PPAR $\gamma$ transactivation. Our data demonstrates that individual PPAR $\gamma$ ligands combined with indivisual RXR ligands can selectively activate response element activity within a single cancer cell type. These data suggest that the effectiveness of PPAR $\gamma$ and RXR as a target for chemotherapeutic treatment will greatly depend on the cell that is treated which opens the possibility of utilizing PPAR $\gamma$ and RXR for targeted gene therapy. 
Abou-Jawde R, Choueiri T, Alemany C, Mekhail T. An Overview of Targeted Treatments in Cancer. Clinical Therapeutics 25 (8) (2003) 2121-2137.

Ahmed W, Orasanu G, Nehra V, Asatryan L, Rader DJ, Ziouzenkova O, and Plutzky J (2006) High-density lipoprotein hydrolysis by endothelial lipase activates PPARalpha: a candidate mechanism for high-density lipoprotein-mediated repression of leukocyte adhesion. Circ Res 98: 490-498.

Aktas H, Halperin JA. Translational Regulation of Gene Expression by n-3 Fatty Acids. Journal of Nutrition 134 (2004) 2487S-2491S.

Barak Y, Liao D, He W, Ong ES, Nelson MC, Olefsky JM, Boland R, and Evans RM (2002) Effects of peroxisome proliferator-activated receptor delta on placentation, adiposity, and colorectal cancer. Proc Natl Acad Sci USA 99: 303-308.

Ben-Dor A, Nahum A, Danilenko M, Giat Y, Stahl W, Martin H, Emmerich T, Noy N, Levy J, Sharoni Y. Effects of acyclo-Rdetinoic Acid and Lycopene on Activation of the Retinoic Acid Receptor and the Proliferation of Mammary Cancer Cells. Archives of Biochemistry and Biophysics 391(2) (2001) 295-302.

Berger JP, Akiyama TE, and Meinke PT (2005) PPARs: therapeutic targets for metabolic disease. Trends Pharmacol Sci 26: 102-107.

Bischoff ED, Gottardis MM, Moon TE, Heyman RA, Lamph WW. Beyond tamoxifen: the retinoid X receptor selective ligand LGD1069 (TARGRETIN) causes complete regression of mammary carcinoma. Cancer Res., 58: 479-484, 1998.

Budhu AS, Noy N. Direct Channeling of Retinoic Acid between Cellular Retinoic AcidBinding Protein II and Retinoic Acid Receptor Sensitizes Mammary Carcinoma Cells to Retinoic Acid-Induced Growth Arrest. Molecular and Cellular Biology 22(8) (2002) 2632-2641.

Burri BJ, Clifford AJ. Carotenoid and retinoid metabolism: insights from isotope studies. Archives of Biochemistry and Biophysics 430 (2004) 110-119.

Chajès V, Sattler W, Stranzl A, Kostner GM. Influence of n-3 fatty acids on the growth of human breast cancer cells in vitro: relationship to peroxides and vitamin E. Breast Cancer Res. Treat. 34 (1995), pp. 199-212.

Chamras H, Ardashian A, Heber D, Glaspy JA. Fatty acid modulation of MCF-7 human breast cancer cell proliferation, apoptosis and differentiation. Journal of Nutritional Biochemistry 13 (2002) 711-716.

Cho Y, Tighe AP, Talmage DA, Retinoic acid induced growth arrest of human breast carcinoma cells requires protein kinase $\mathrm{C}$ alpha expression and activity, J. Cell. Physiol. 172 (1997), pp. 306-313. 
Chou CJ, Haluzik M, Gregory C, Dietz KR, Vinson C, Gavrilova O, and Reitman ML (2002) WY14,643, a peroxisome proliferator-activated receptor alpha (PPARalpha) agonist, improves hepatic and muscle steatosis and reverses insulin resistance in lipoatrophic A-ZIP/F-1 mice. J Biol Chem 277: 24484-24489.

Christian P. Micronutrients and reproductive health issues: an international perspective. J Nutr. 2003 Jun;133(6):1969S-1973S. Review.

Chujo H, Yamasaki M, Nou S, Koyanagi N, Tachibana H, Yamada K. Effect of conjugated linoleic acid isomers on growth factor-induced proliferation of human breast cancer cells. Cancer Letters 202 (2003) 81-87.

Cohen LA, Thompson DO, Maeura Y, Choi K, Blank ME, Rose DP. Dietary fat and mammary cancer. I. Promoting effects of different dietary fats on N-nitrosomethylureainduced rat mammary tumorigenesis. J. Natl. Cancer Inst. 77 (1986), pp. 33-42.

Danforth Jr. DN, All trans-retinoic acid acts synergistically with hydroxytamoxifen and transforming-growth factor beta to stimulate apoptosis in MCF-7 breast cancer cells, $J$. Endocrinol. 183 (2004), pp. 395-404.

Dawson MI, Chao W, Hobbs PD, Zhang X. Effects of trans-retinoic acid, 9-cis-retinoic acid, 1a,25-(dihydroxy)vitamin D3 and a novel apoptosis-inducing retinoid on breast cancer and endothelial cell growth. Cancer Letters 133 (1998) 1-8.

Devchand PR, Ijpenberg A, Devesvergne B, Wahli W. PPARs: nuclear receptors for fatty acids, eicosanoids, and xenobiotics. Adv Exp Med Biol. 1999;469:231-6.

Durgam VR, Fernandes G. The growth inhibitory effect of conjugated linoleic acid on MCF-7 cells is related to estrogen response system. Cancer Letters 116 (1997) 121-130.

Freemantle SJ, Spinella MJ, Dmitrovsky E. Retinoids in cancer therapy and chemoprevention: promise meets resistance. Oncogene. 2003 Oct 20;22(47):7305-15. Review.

Gerber M. Olive oil, monounsaturated fatty acids and cancer. Cancer Letters 114 (1997) 91-92.

Guerre-Millo M, Gervois P, Raspe E, Madsen L, Poulain P, Derudas B, Herbert JM, Winegar DA, Willson TM, Fruchart JC, et al. (2000) Peroxisome proliferator-activated receptor alpha activators improve insulin sensitivity and reduce adiposity. J Biol Chem 275: 16638-16642.

Jimenez-Lara AM, Clarke N, Altucci L, Gronemeyer H. Retinoic-acid-induced apoptosis in leukemia cells. Trends in Molecular Medicine 10 (10) (2004) 508-515.

Katan MB. Omega-6 polyunsaturated fatty acids and coronary heart disease. Am J Clin Nutr. 2009 May;89(5):1283-4. Epub 2009 Mar 25. 
Kachhap SK, Dange P, Ghosh SN. Effect of n-6 polunsaturated fatty acid (linoleic acid) on BRCA1 gene expression in MCF-7 cell line. Cancer Letters 154 (2000) 115-120.

Kerner J, Hoppel C. Fatty acid import into mitochondria. Biochemica et Biophysica Acta 1486 (2000) 1-17.

Kersten S, Mandard S, Escher P, Gonzalez FJ, Tafuri S, Desvergne B, and Wahli W (2001) The peroxisome proliferator-activated receptor alpha regulates amino acid metabolism. FASEB J 15: 1971-1978.

Kersten S, Seydoux J, Peters JM, Gonzalez FJ, Desvergne B, and Wahli W (1999) Peroxisome proliferator-activated receptor alpha mediates the adaptive response to fasting. J Clin Investig 103: 1489-1498.

Kim H, Haluzik M, Asghar Z, Yau D, Joseph JW, Fernandez AM, Reitman ML, Yakar S, Stannard B, Heron-Milhavet L, et al. (2003) Peroxisome proliferator-activated receptoralpha agonist treatment in a transgenic model of type 2 diabetes reverses the lipotoxic state and improves glucose homeostasis. Diabetes 52: 1770-1778.

Kogai T, Schultz JJ, Johnson LS, Huang M, Brent GA. Retinoic acid induces sodium/iodide symporter gene expression and radioiodide uptake in the MCF-7 breast cancer cell line. Proc Natl Acad Sci USA 97 (2000) 8519-8524.

Korde LA, Calzone KA, Zujewski J. Genetic factors are not the whole story. Postgraduate Medicine 116 (2004).

Kuhajda FP. Fatty-Acid Synthase and Human Cancer: New Perspectives on Its Role in Tumor Biology. Nutrition 16 (2000) 202-208.

Kushi L, Giovannucci E. Dietary Fat and Cancer. Am J Med 113(9b) (2002) 63s-70s.

Leblanc BP, Stunnenberg HG. 9-cis retinoic acid signaling: changing partners causes some excitement. Genes Dev., 9: 1811-1816, 1995.

Leelawat K, Ohuchida K, Mizumoto K, Mahidol C, Tanaka M. All-trans retinoic acid inhibits the cell proliferation but enhances the cell invasion through up-regulation of cmet in pancreatic cancer cells. Cancer Letters (2004) 1-8.

Lefebvre P, Chinetti G, Fruchart JC, and Staels B (2006) Sorting out the roles of PPAR alpha in energy metabolism and vascular homeostasis. J Clin Investig 116: 571-580.

Lehmann JM, Dawson MI, Hobbs PD, Husmann M, Pfahl M. Identification of retinoids with nuclear receptor subtype selective activities. Cancer Res., 51: 4804-4809, 1991.

Lei M, The H. Retinoids and retinoic acid receptor in cancer. EJC Supplements 1 (2) (2003) 13-18. 
Liu Y, Lee M, Wang H, Li Y, Hashimoto Y, Klaus M, Reed JC, Zhang X. Retinoic Acid Receptor B Mediates the Growth-Inhibitory Effect of Retinoic Acid by Promoting Apoptosis in Human Breast Cancer Cells. Molecular and Cellular Biology 16(3) (1996) 1138-1149.

Maggiora M, Bologna M, Ceru MP, Possati L, Angelucci A, Cimni A, Miglietta A, Bozzo F, Margiotta C, Muzio G, Canuto RA. An overview of the effect of linoleic and conjugated linoleic acids on the growth of several human tumor cell lines, Int. J. Cancer 112 (2004), pp. 909-919.

Makowski L, Hotamisligil GS. Fatty Acid Binding Proteins - The Evolutionary Crossroads of Inflammatory and Metabolic Responses. Journal of Nutrition 134 (2004) 2464S- 2468S.

Mangelsdorf DJ, Evans RM. The RXR heterodimers and orphan receptors. Cell, 83: 841850, 1995.

Mensink RP. Effects of products made from a high-palmitic acid, trans-free semiliquid fat or a high-oleic acid, low-trans semiliquid fat on the serum lipoprotein profile and on C-reactive protein concentrations in humans. Eur J Clin Nutr. 2008 May;62(5):617-24. Epub 2007 Apr 18.

McClelland GB. Fat to the fire: the regulation of lipid oxidation with exercise and environmental stress. Comparative Biochemistry and Physiology, Part B 139 (2004) 443460.

Menendez JA, Barbacid M, Montero S, Sevilla E, Escrich E, Solanas M, Cortes-Funes H, Colomer R. Effects of gamma-linolenic acid and oleic acid on paclitaxel cytotoxicity in human breast cancer cells. European Journal of Cancer 37 (2001) 402-413.

Merino R, Hurle JM. The molecular basis of retinoid action in tumors. Trends in Molecular Medicine 9 (12) (2003) 509-511.

Moller DE, Berger JP. Role of PPARs in the regulation of obesity-related insulin sensitivity and inflammation. Int J Obes Relat Metab Disord. 2003 Dec;27 Suppl 3:S1721. Review.

Murff HJ, Byrne D, Syngal S. Cancer Risk Assessment: Quality and Impact of the Family History Interview. American Journal of Preventive Medicine 27(3) (2004) 239245.

Nicol CJ, Yoon M, Ward JM, Yamashita M, Fukamachi K, Peters JM, Gonzalez FJ. PPARgamma influences susceptibility to DMBA-induced mammary, ovarian and skin carcinogenesis. Carcinogenesis. 2004 Sep;25(9):1747-55. Epub 2004 Apr 8.

Okamoto K, Andreola F, Chiantore MV, Dedrick RL and De Luca LM, Differences in uptake and metabolism of retinoic acid between estrogen receptor-positive and -negative human breast cancer cells, Cancer Chemother. Pharmacol. 46 (2000), pp. 128-134. 
Paik J, Blaner WS, Swisshelm K. Cis-retinol dehydrogenase: 9-cis-retinol metabolism and its effect on proliferation of human MCF7 breast cancer cells. Experimental Cell Research 303 (2005) 183-196.

Pegorier JP, Le May C, Girard J. Control of Gene Expression by Fatty Acids. Journal of Nutrition 134 (2004) 2444S-2449S.

Quadro L, Hamberger L, Colantuoni V, Gottesman ME, Blaner WS. Understanding the physiological role of retinol-binding protein in vitamin A metabolism using transgenic and knockout mouse models.

Reddy JK and Hashimoto T (2001) Peroxisomal beta-oxidation and peroxisome proliferator-activated receptor alpha: an adaptive metabolic system. Annu Rev Nutr 21: 193-230.

Rose DP, Connolly JM. Omega-3 fatty acids as cancer chemopreventive agents. Pharmacology \& Therapeutics 83 (1999) 217-244.

Reyes N, Reyes I, Tiwari R, Geliebter J. Effect of linoleic acid on proliferation and gene expression in the breast cancer cell line T47D. Cancer Letters 209 (2004) 25-35.

Sanderson IR. Short Chain Fatty Acid Regulaton of Signaling Genes Expressed by the Intestinal Epithelium. Journal of Nutrition 134 (2004) 2450S-2454S.

Semba RD, de Pee S, Panagides D, Poly O, Bloem MW. Risk factors for xerophthalmia among mothers and their children and for mother-child pairs with xerophthalmia in Cambodia. Arch Ophthalmol. 2004 Apr;122(4):517-23.

Serrano D, Perego E, Costa A, Decensi A. Progress in chemoprevention of breast cancer. Critical Reviews in Oncology/Hematology 49 (2004) 109-117.

Silveira ER, Moreno FS. Natural retinoids and B-carotene: From food to their actions on gene expression. J. Nutr. Biochem. 9 (1998) 446-456.

Simopoulos AP. The importance of the ratio of omega-6/omega-3 essential fatty acids. Biomed Pharmacother 56 (2002) 365-379.

Sommer KM, Chen LI, Treuting PM, Smith LT, Swisshelm K. Elevated retinoic acid receptor B4 protein in human breast tumor cells with nuclear and cytoplasmic localization. Proc Natl Acad Sci USA 96 (1999) 8651-8656.

Staels B, Vu-Dac N, Kosykh VA, Saladin R, Fruchart JC, Dallongeville J, and Auwerx J (1995) Fibrates downregulate apolipoprotein C-III expression independent of induction of peroxisomal acyl coenzyme A oxidase. A potential mechanism for the hypolipidemic action of fibrates. J Clin Investig 95: 705-712. 
Stanley TB, Leesnitzer LM, Montana VG, Galardi CM, Lambert MH, Holt JA, Xu HE, Moore LB, Blanchard SG, and Stimmel JB (2003) Subtype specific effects of peroxisome proliferator-activated receptor ligands on corepressor affinity. Biochemistry 42: 92789287.

Sun SY, Yue P, Dawson MI, Shroot B, Michel S, Lamph WW, Heyman RA, Teng M, Chandraratna RAS, Shudo K, Hong WK, Lotan R. Differential effects of synthetic nuclear retinoid receptor selective retinoids on the growth of human non-small cell lung carcinoma cells. Cancer Res., 57: 4931-4939, 1997.

Takitani K, Koh M, Inoue A, Kawakami C, Kuno T, Tamai H. Pharmacokinetics of alltrans retinoic acid in adults and children with acute promyelocytic leukemia. Am J Hematol. 2006 Sep;81(9):720-1.

Thoennes SR, Tate PL, Price TM, Kilgore MW. Differential transcriptional activation of peroxisome proliferators-activated receptor gamma by omega-3 and omega- 6 fatty acids in MCF-7 cells. Molecular and Cellular Endocrinology 160 (2000) 67-73.

Thupari JN, Pinn ML, Kuhajda FP. Fatty Acid Synthase Inhibition in Human Breast Cancer Cells Leads to Malonyl-CoA-Induced Inhibition of Fatty Acid Oxidation and Cytotoxicity. Biochemical and Biophysical Research Communications 285 (2001) 217223.

Thurnham DI, McCabe GP, Northrop-Clewes CA, Nestel P. Effects of subclinical infection on plasma retinol concentrations and assessment of prevalence of vitamin $\mathrm{A}$ deficiency: meta-analysis. Lancet. 2003 Dec 20;362(9401):2052-8.

Tighe AP, Talmage DA. Retinoids arrest breast cancer cell proliferation: retinoic acid selectively reduces the duration of receptor tyrosine kinase signaling. Experimental Cell Research 301 (2004) 147-157.

Vu-Dac N, Gervois P, Torra IP, Fruchart JC, Kosykh V, Kooistra T, Princen HM, Dallongeville J, Staels B. Retinoids increase human apo C-III expression at the transcriptional level via the retinoid $\mathrm{X}$ receptor. Contribution to the hypertriglyceridemic action of retinoids. J Clin Invest. 1998 Aug 1;102(3):625-32.

Walker WA, Blackburn G, Symposium Introduction: Nutrition and Gene Regulation. Journal of Nutrition 134 (2004) 2434S-2436S.

Wayne SJ, Lopez ST, Butler LM, Baumgartner KB, Baumgartner RN, Ballard-Barbash R. Changes in Dietary Intake after Diagnosis of Breast Cancer. J AM Diet Assoc 104 (2004) 1561-1568.

Weinbrenner T, Fito M, Torre R, Saez G, Rijken P, Tormos C, Coolen S, Albaladejo MF, Abanades S, Schroder H, Marrugat J, Covas M. Olive Oils High in Phenolic Compounds Modulate Oxidative/Antioxidative Status in Men. Journal of Nutrition 134 (2004) 23142321. 
Willett WC. The role of dietary n-6 fatty acids in the prevention of cardiovascular disease. J Cardiovasc Med (Hagerstown). 2007 Sep;8 Suppl 1:S42-5. Review.

Wiseman RA. Breast Cancer: Critical data analysis concludes that estrogens are not the cause, however lifestyle changes can alter risk rapidly. Journal of Clinical Epidemiology 57 (2004) 766-772.

\section{Appendix A}

\section{Cyquant Cell Proliferation Protocol}

1. On day of experiment, decide number of wells to be assayed. This will depend on number of treatments and number of plates. (For example, look to image below.)

2. Obtain a plastic (preferably opaque) bottle, and aluminum foil.

3. Dilute the stock 20x Lysis Buffer Solution to 1X, so add $1 \mathrm{ml}$ of buffer to $19 \mathrm{ml}$ of Nuclease free DI water. (note this is enough for 100 assays at 200ul each)

4. Next make a 400 fold dilution with the Green Dye solution by adding 50ul of dye to the $1 \mathrm{x}$ lysis buffer. Cover with foil. Now we are ready.

5. Use this solution within 2 hours of creation, and keep covered with foil for light protection.

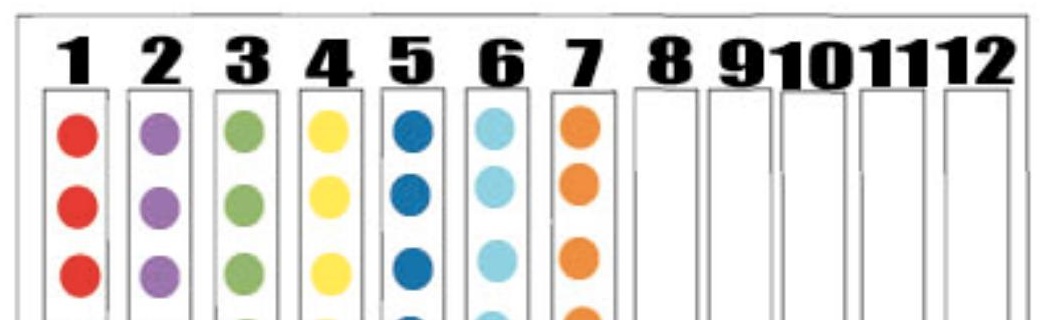




\section{Cell culture prior to day of assay}

6. Obtain a 96 well, or 48 well plate.

7. Seed the wells with 5000 cells per well as obtained from a hemacytometer count. (Hemacytometer protocol is available and separate)

8. Grow the cells with treatments (as described later) for specified durations.

9. Blot the media from the wells, and freeze immediately at $-70 \mathrm{C}$ for each time period.

\section{Day of assay protocol}

10. On day of assay, obtain plate from freezer and let thaw, then add 200 ul of the working solution to each well to be assayed.

11. Let mix and incubate for $5 \mathrm{~min}$, and cover the plate with foil to protect from light.

12. Then use microplate reader to measure fluorescence with settings at $480 \mathrm{~nm}$ excitation and 520nm emission maxima.

\section{Standard Curve Creation}

1. Obtain 96 or 48 well plate.

2. Use hemacytometer to count cells from a confluent flask.

3. Seed wells with 500, 1000, 2000, 5000, and 10000 cells per well

4. Let cells adhere and incubate for 24 hours, then freeze.

5. Run assay as described above, and pray for a linear relationship.

6. Plate will be seeded as shown below. 


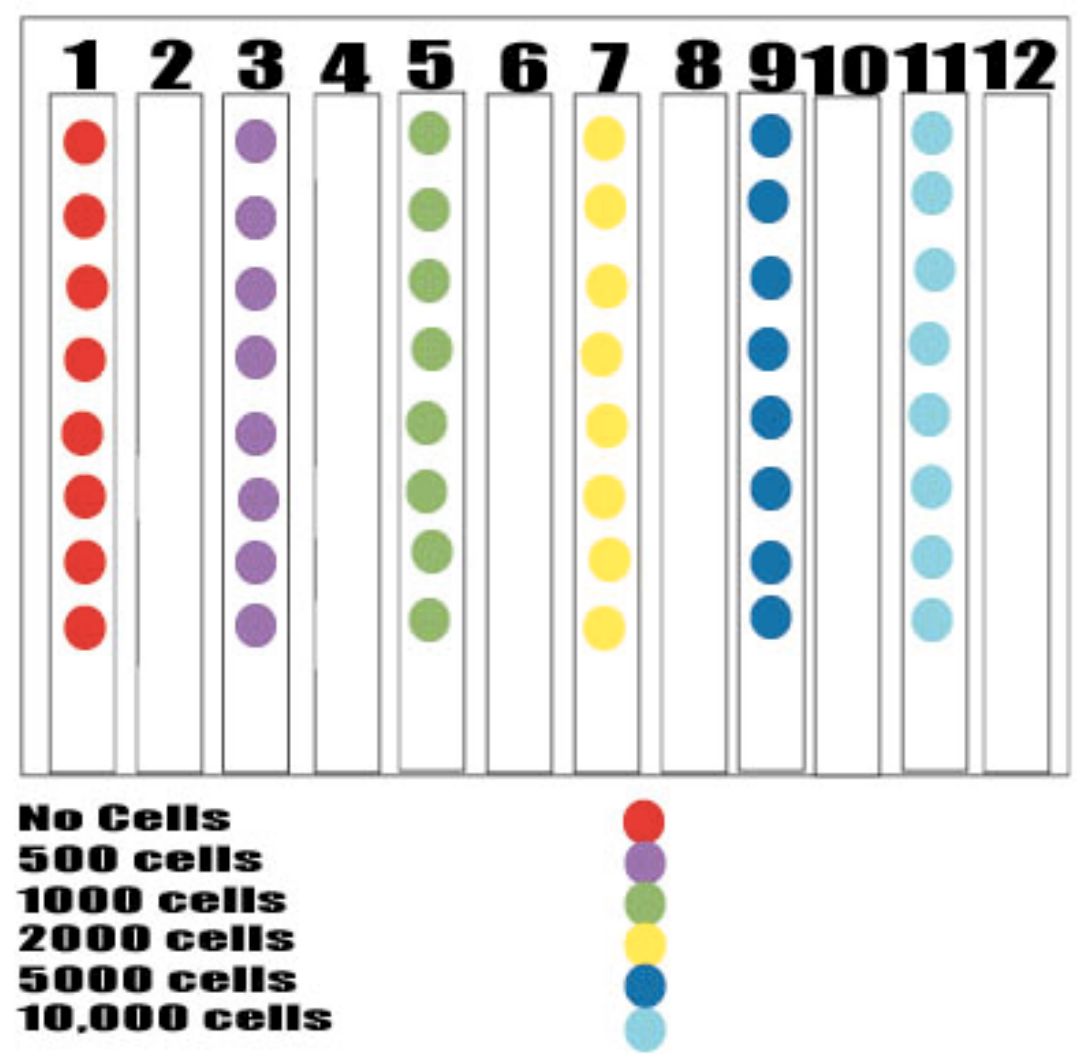

\section{Appendix B}

\section{Hemacytometer Protocol}

Obtain 1 flask/plate of cells, and aspirate off media. Add $5 \mathrm{cc}$ of Trypsin and place in incubator for 7-10 minutes.

Add $15 \mathrm{cc}$ of new media to trypsinized cells in flask, and mix via pipette.

Aliquot $10 \mathrm{cc}$ of cells + media into a new $15 \mathrm{cc}$ conical tube, and repeat for other $10 \mathrm{cc}$ left in flask.

Take $215 \mathrm{cc}$ conical tubes containing $10 \mathrm{cc}$ of cells + media and place in centrifuge directly across from eachother for balance. Set to spin at $1800 \mathrm{rpm}$ for 5 minutes. Set acceleration at setting 2 , and deceleration at setting 9 at 18 degrees Celsius. (This is for Eppendorf centrifuge) 
Take $15 \mathrm{cc}$ tubes with visible cell pellets back to sterile environment to aspirate off media, and re-suspend cell pellet in $1 \mathrm{cc}$ of new media. (Do this using a transfer pipette)

With new transfer pipette, take small sample of cells plus media and slowly release onto hemacytometer. (The slide should have a coverslip on at this point, and is designed to disperse evenly due to small "channel" in glass)

Place on upright (not inverted) microscope and view on the $5 \mathrm{X}$ objective lens to see cells. Optimal viewing found on $10 \mathrm{x}$ objective lens.

To count cells, first find center square with a $5 \times 5$ square profile. Count each corner square, and pick one more square in middle. (Note, this tactic only works if cells appear to be evenly distributed across slide... which they should!) Later the number is multiplied by 5 to account for other squares.

Number will most likely be between 50-150. Then use the following equation:

(cell \# counted) $\times 5 \times 10^{\wedge} 4 \times 1 \mathrm{ml}=\#$ of cells in suspension

Ex: 57 cells $\times 5 \times 10^{\wedge} 4 \times 1 \mathrm{ml}=2.85 \times 10^{\wedge} 6$

Next, decide how much to aliquot for each well on a 96 well plate.

Ex: let's assume we want 5,000 cells per well.

$.05 \times 10^{\wedge} 6 / 2,85 \times 10^{\wedge} 6=.018 \mathrm{ml}$ or.... 18ul per well.

Max well volume should not exceed a ceiling, Of $270 \mathrm{ul}$. Therefore, the media warmed before adding cells must be less than 252 ul in this case for each well.

\section{Appendix C}

\section{Complete Experiment Results}

The experiment concluded much more data then reported in the results section of Chapter 4. The results below are day to day results that were used for final analysis. As reported earlier, the results are described by either a single treatment on day one, or daily treatments over 72 hours. Each treatment is indicated as well.

Cell Growth Treatment: Blank

Day 1

Day 2

Day 3 $\begin{array}{ll}\text { Day } 1 & \text { Daily } \\ \text { treatment } & \text { Treatment }\end{array}$

$18963751.5 \quad 18963751.5$

$21281242.5 \quad 21281242.5$

$27134548 \quad 27134548$ 
Cell Growth (DMSO Control)

Day 1

Day 2

Day 3
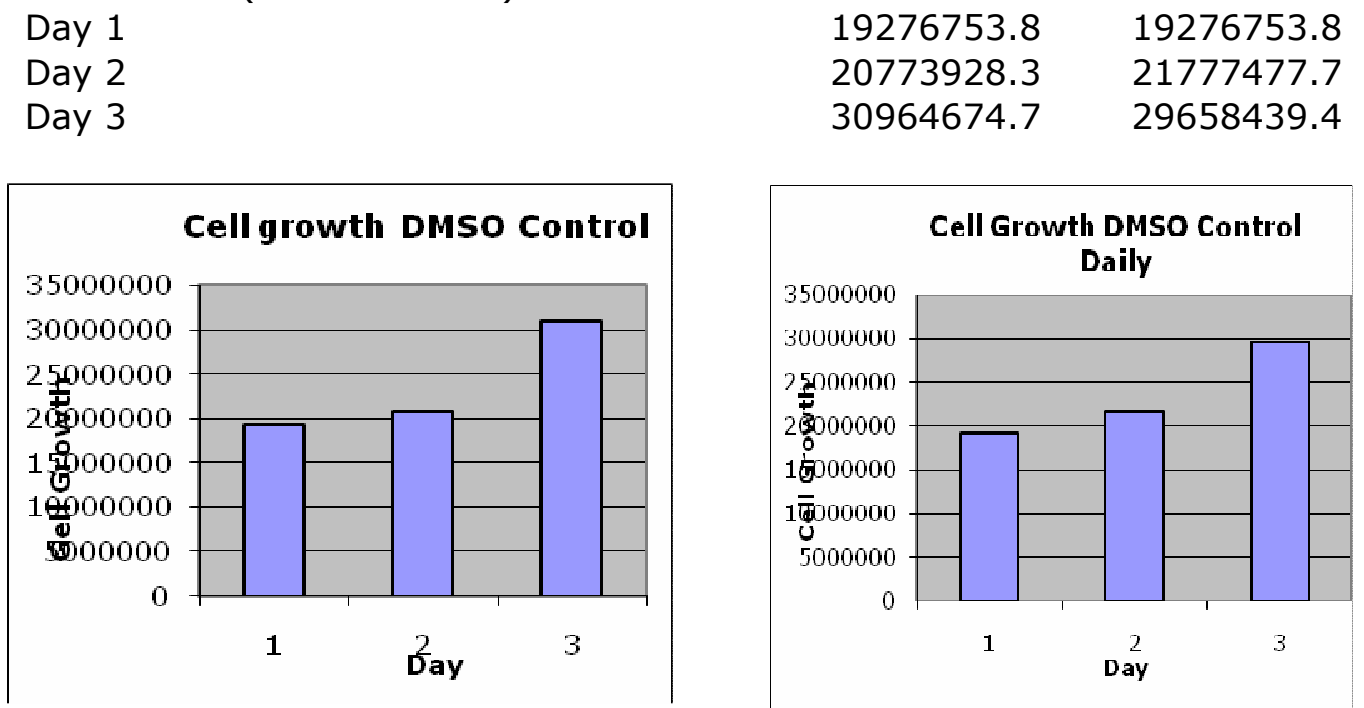

Cell Growth (ATRA 1uM)

Day 1

Day 2

Day 3

$\begin{array}{rr}16084480 & 16084480 \\ 19283732.7 & 15140571 \\ 26206974.6 & 9057623.09\end{array}$
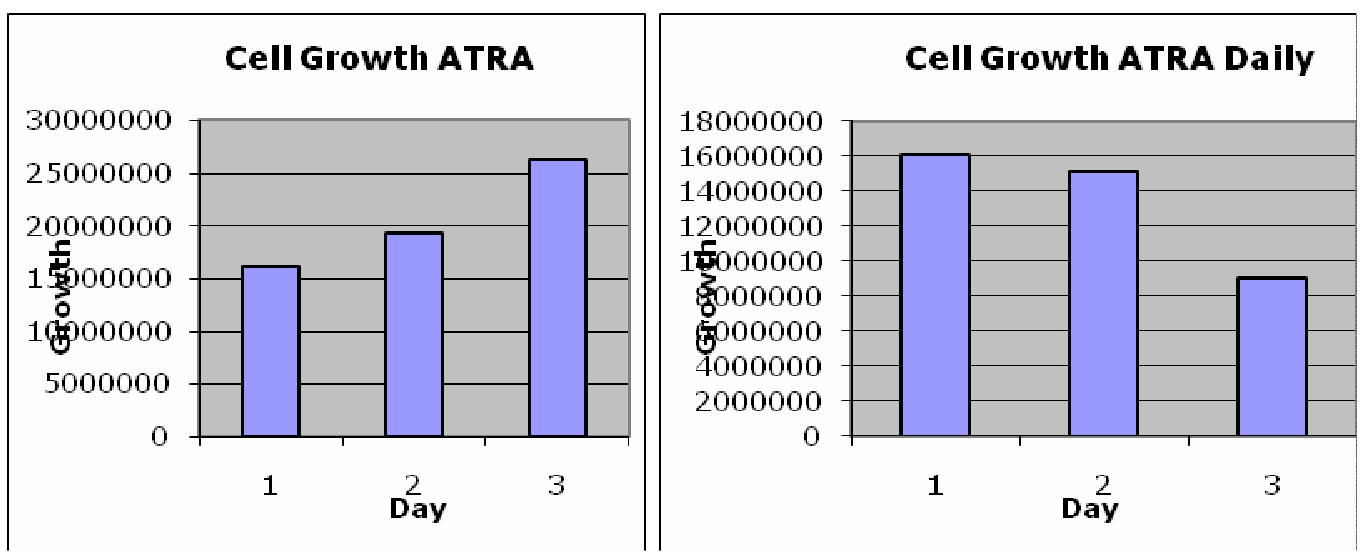

Cell Growth (Linolenic 2.5 uM)

Day 1

Day 2

Day 3

$\begin{array}{rr}18397367.7 & 18397367.7 \\ 19290527 & 17852295.3 \\ 25327786.1 & 19938678.6\end{array}$



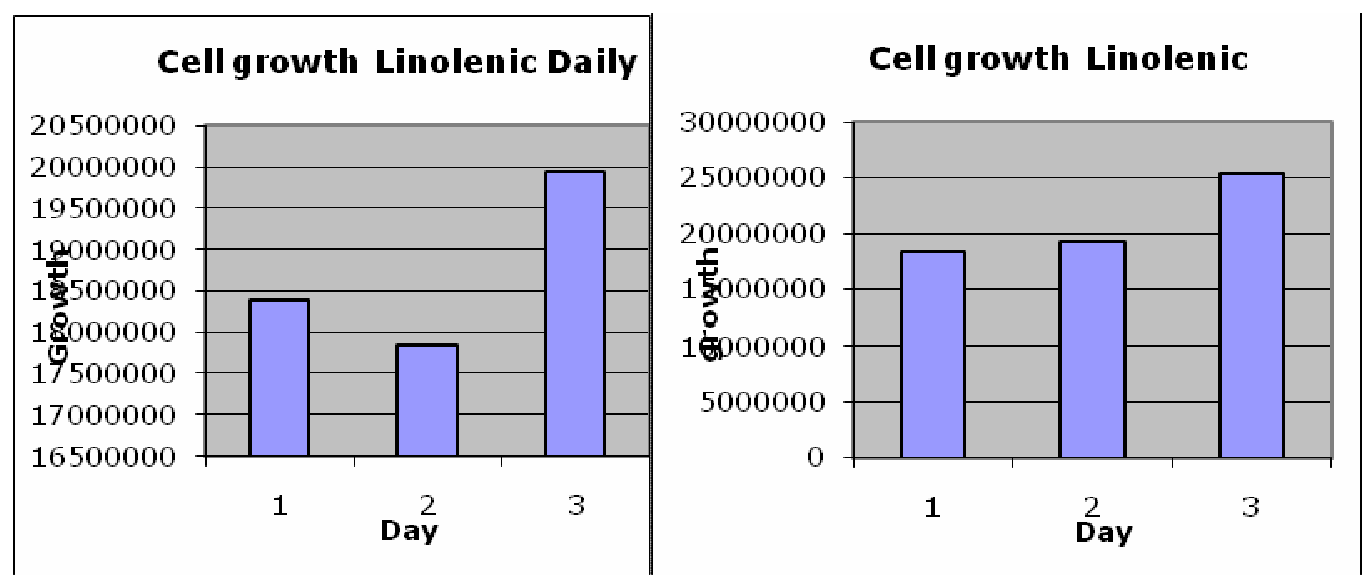

Cell Growth (Linoleic 2.5 uM)

Day 1

Day 2

Day 3
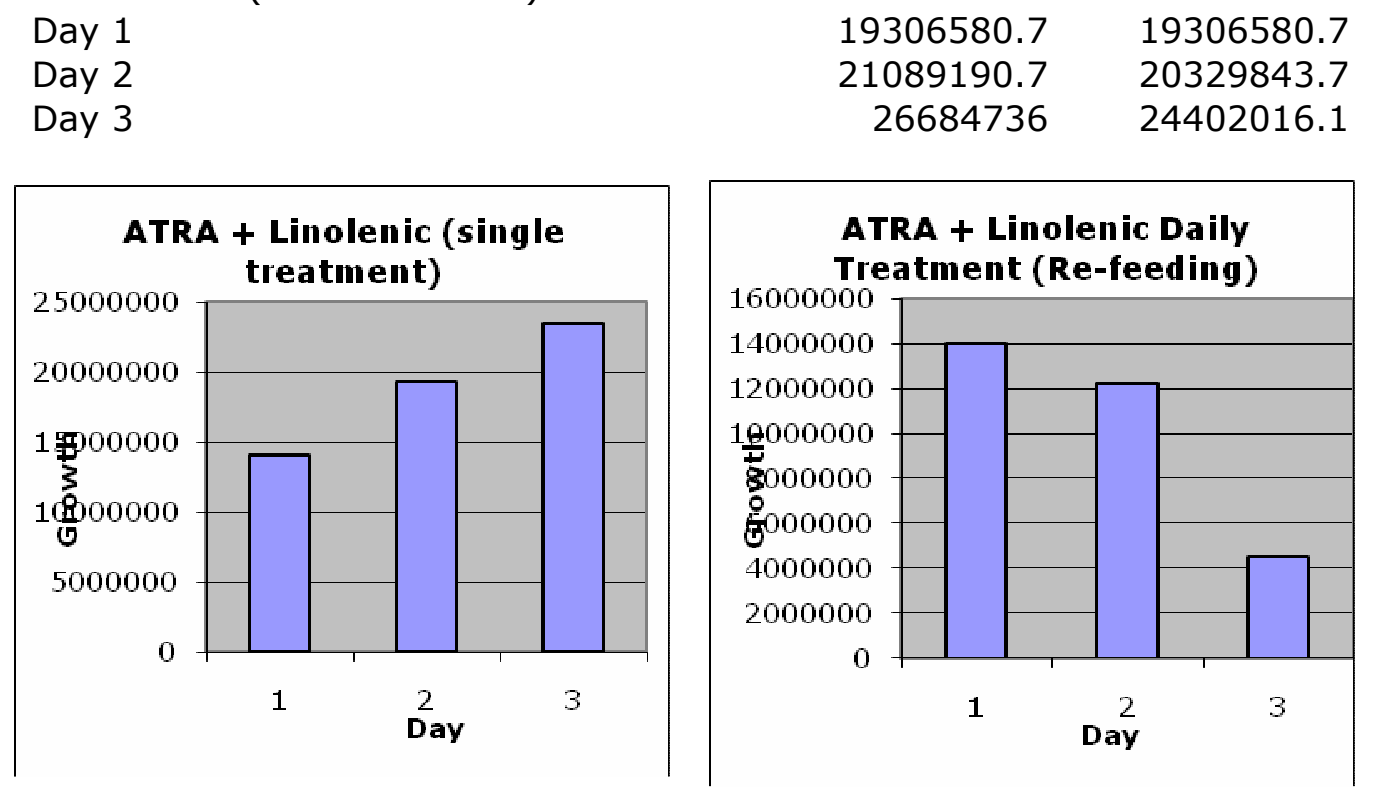

Cell Growth (ATRA 1 uM + Linolenic 2.5 uM)

Day 1

Day 2

Day 3

$\begin{array}{rr}13996046.2 & 13996046.2 \\ 19264504.3 & 12188983 \\ 23443646.3 & 4499775.95\end{array}$




\section{Appendix D}

\section{Liposome Delivery System Results}

The research conducted here was in calloboration with the Dairy Products Technology Center at Cal Poly, San Luis Obispo during 2006-2007. Callaborators included Dr. Susan Hawk, Dr. Rafeal Jimenez, David Brown, and Jessica Yee. Other technicians included in the study were Selena Tinga, and Diana Rios.

The study yielded promising results, and would be an excellent starting point for future research. The project used a SuperCritical Fluid Extraction method to isolate milk lipids. These lipids were then manipulated through High Pressure Homogenization to creat Liposomes. The liposomes were also created with All-trans retinoic Acid as a nutrient to be delivered in vitro. Results were as follows:

By Treatment

Treatment

Imidazole

Ethanol

2.5 UM ATRA

SE (SFE emulsiflex)

SAE (SFE+ATRA+emulsiflex)

SS (SFE sonicated)

SAS (SFE+ATRA+sonicated)

BE (buttermilk powder + emulsiflex)

BAE (Buttermilk powder + ATRA + emulsiflex)

BS (Buttermilk powder + sonicated)

BAS (Buttermilk powder + ATRA

+sonicated)
Cell Growth (24hrs)

21981333.5

20781992.5

15140571

19701002.5

14740598

20822992.5

14999579

20788888.5

21001982.5

19997654.5

17140987
CONTROL 21281242.5 21281242.5 21281242.5 21281242.5 21281242.5 21281242.5 21281242.5 21281242.5

21281242.5 21281242.5

21281242.5 
By method

Control

Imidazole

Ethanol

2.5 UM ATRA

SAE (SFE+ATRA+emulsiflex)

SAS (SFE+ATRA+sonicated)

BAE (Buttermilk powder + ATRA + emulsiflex)

BAS (Buttermilk powder + ATRA

+sonicated)

SE (SFE emulsiflex)

SS (SFE sonicated)

BE (buttermilk powder + emulsiflex)

BS (Buttermilk powder + sonicated)
21281242.5

21981333.5

20781992.5

15140571

14740598

14999579

21001982.5

17140987

19701002.5

20822992.5

20788888.5

19997654.5
21281242.5

21281242.5

21281242.5

21281242.5

21281242.5

21281242.5

21281242.5

21281242.5

21281242.5

21281242.5

21281242.5

21281242.5

\section{MCF-7 Cell Growth Liposome (ATRA Grouped)}

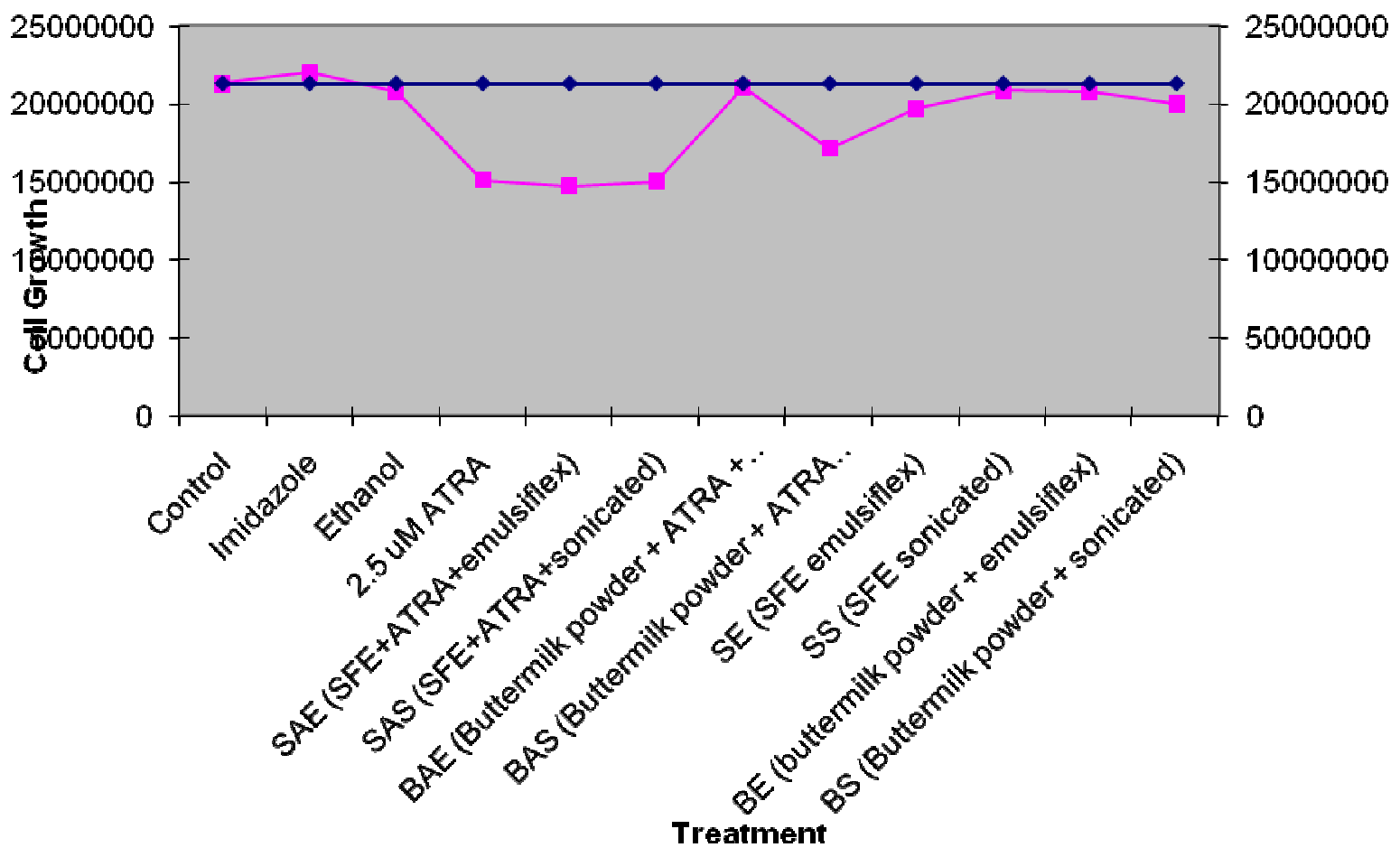




\section{MCF-7 Cell Growth Liposomes (By Method)}

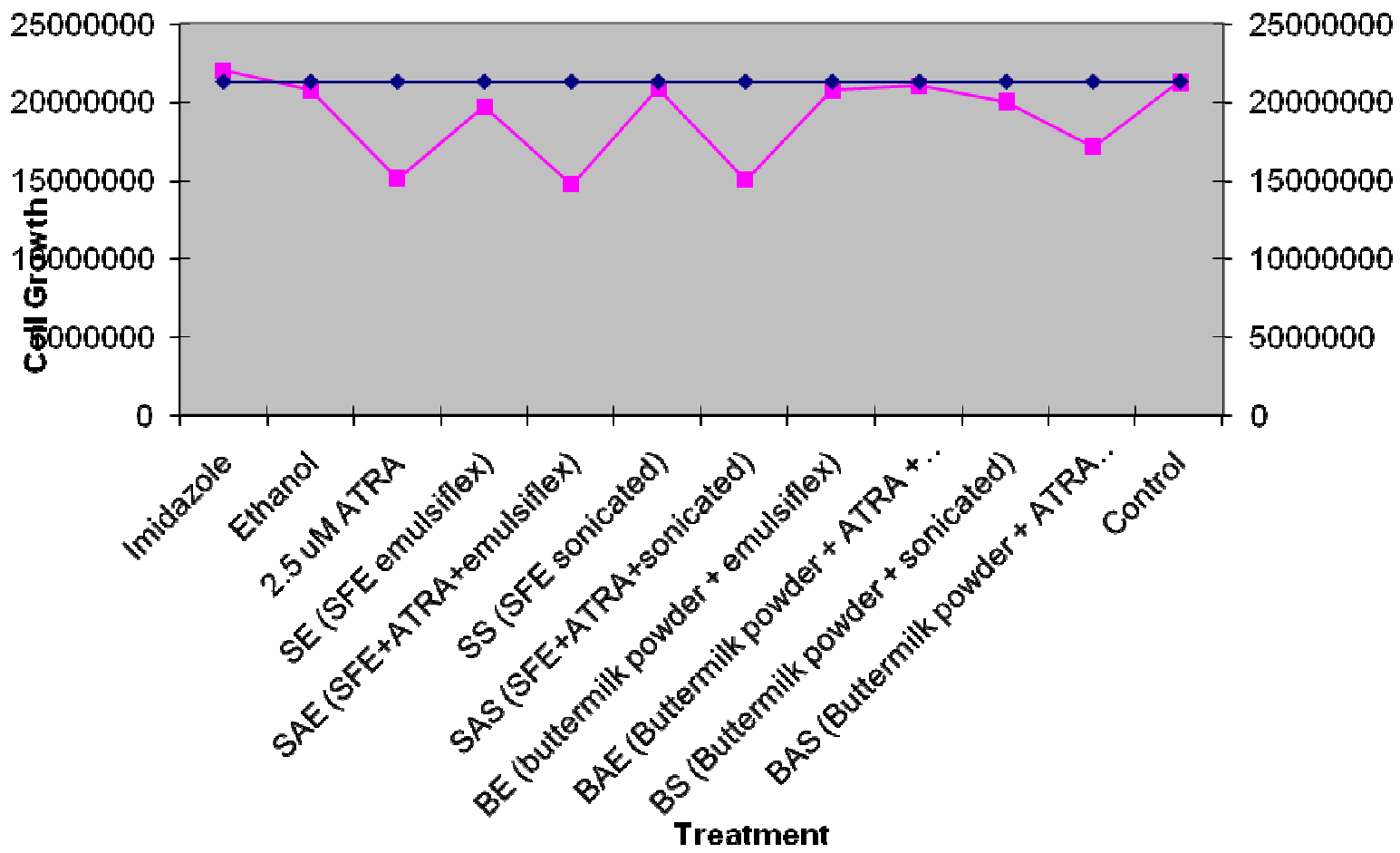

\section{Appendix E}

\section{Minitab Output}

\section{General Linear Model: Count versus Treatment, Application}

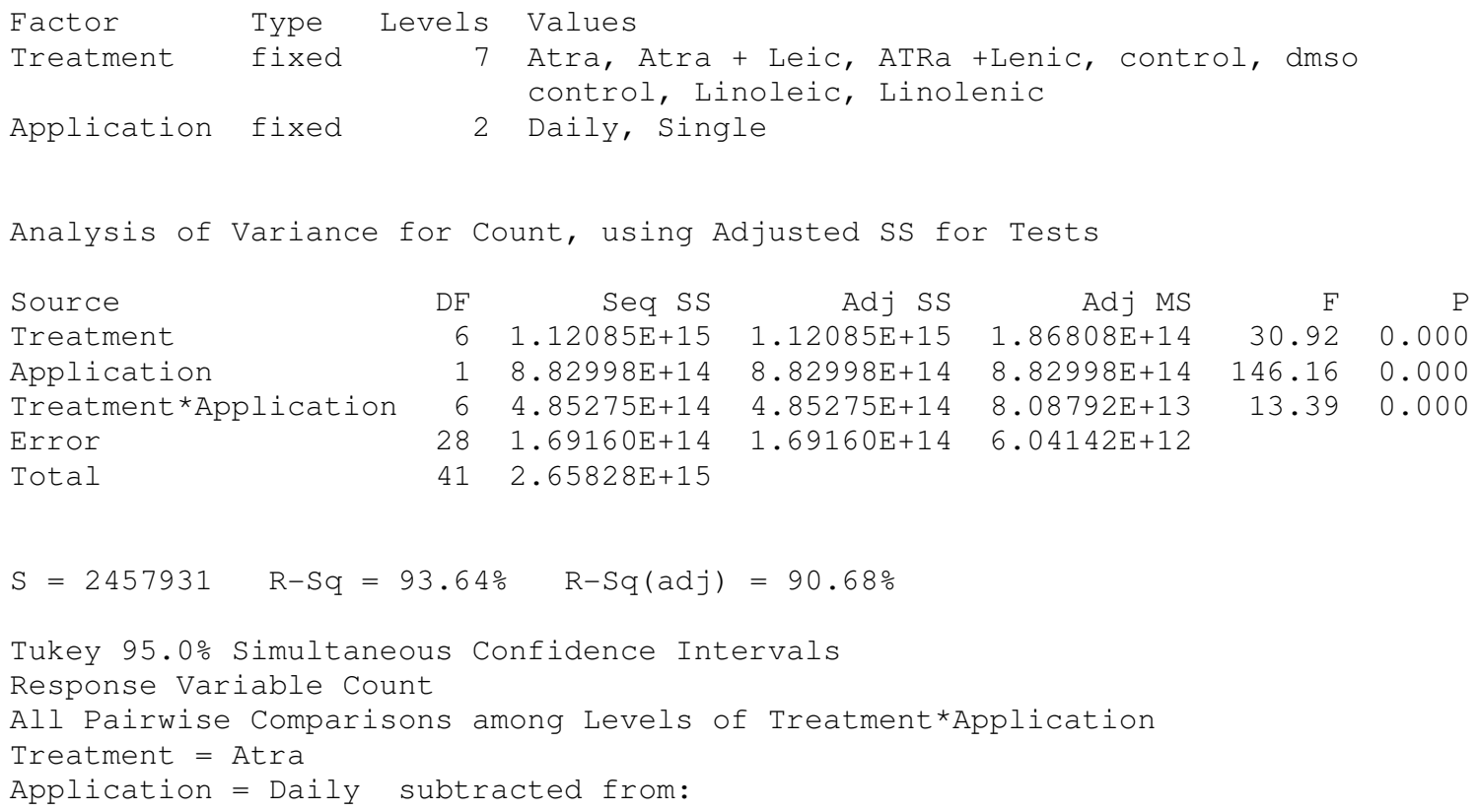




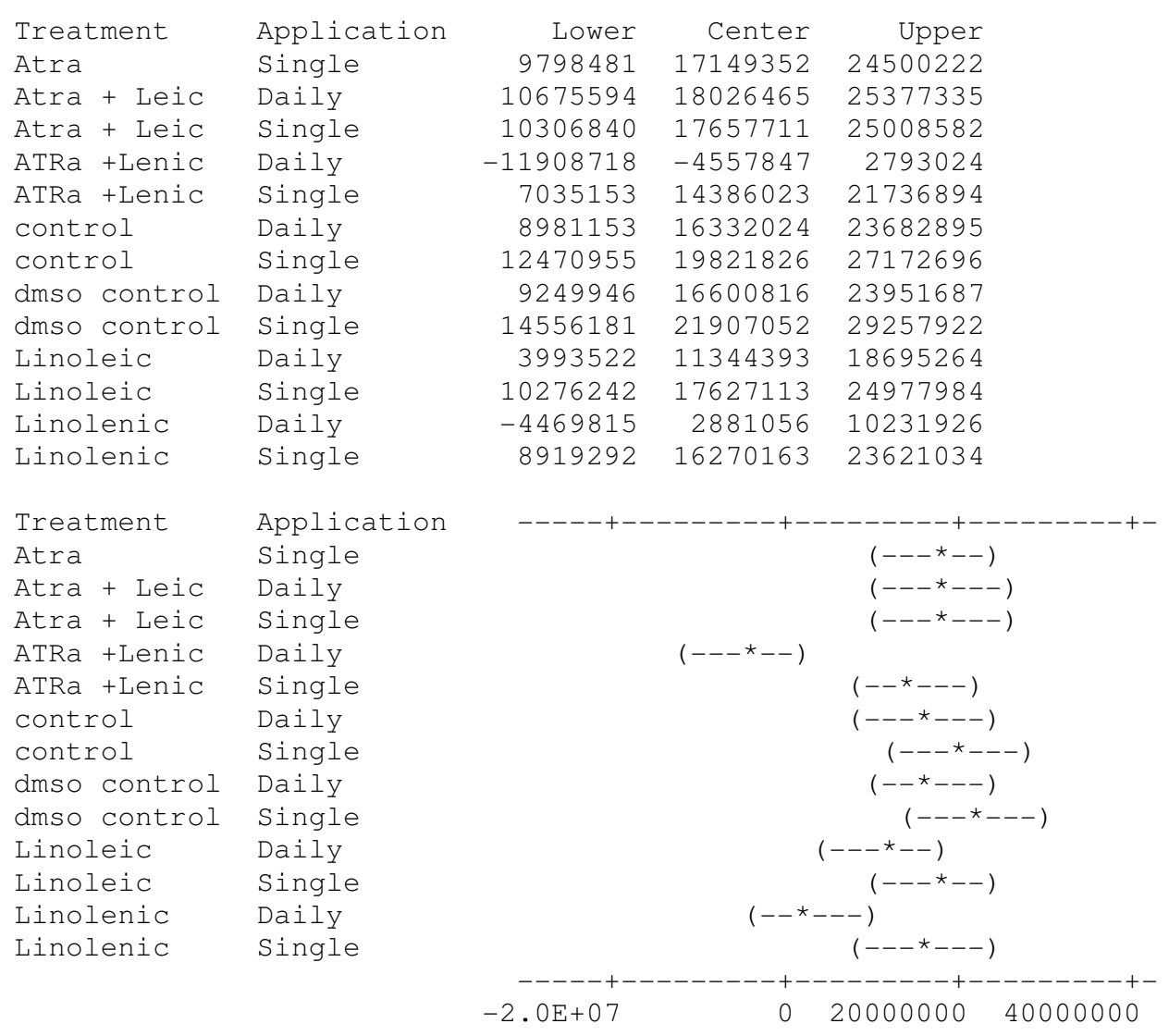

\begin{tabular}{|c|c|c|c|c|}
\hline Treatment & Application & Lower & Center & Upper \\
\hline Atra + Leic & Daily & -6473758 & 877113 & 8227984 \\
\hline Atra + Leic & Single & -6842511 & 508359 & 7859230 \\
\hline ATRa +Lenic & Daily & -29058069 & -21707199 & -14356328 \\
\hline ATRa +Lenic & Single & -10114199 & -2763328 & 4587542 \\
\hline control & Daily & -8168198 & -817327 & 6533543 \\
\hline control & Single & -4678397 & 2672474 & 10023345 \\
\hline dmso control & Daily & -7899406 & -548535 & 6802335 \\
\hline dmso control & Single & -2593171 & 4757700 & 12108571 \\
\hline Linoleic & Daily & -13155829 & -5804959 & 1545912 \\
\hline Linoleic & Single & -6873109 & 477761 & 7828632 \\
\hline Linolenic & Daily & -21619167 & -14268296 & -6917425 \\
\hline Linolenic & Single & -8230059 & -879189 & 6471682 \\
\hline Treatment & Application & \\
\hline Atra + Leic & Daily & & & \\
\hline Atra + Leic & Single & \multicolumn{3}{|c|}{$\begin{array}{l}\left(--^{\star}---\right) \\
\left(--^{\star}---\right)\end{array}$} \\
\hline ATRa +Lenic & Daily & \multicolumn{3}{|l|}{$(---\star---)$} \\
\hline ATRa +Lenic & Single & \multicolumn{3}{|c|}{$(---\star--)$} \\
\hline control & Daily & \multicolumn{3}{|c|}{$(---\star--)$} \\
\hline control & Single & \multicolumn{3}{|c|}{$(--\star---)$} \\
\hline dmso control & Daily & \multicolumn{3}{|c|}{$(---\star--)$} \\
\hline dmso control & Single & \multicolumn{3}{|c|}{$(--\star---)$} \\
\hline Linoleic & Daily & \multicolumn{3}{|c|}{$(---\star---)$} \\
\hline Linoleic & Single & \multicolumn{3}{|c|}{$(--\star---)$} \\
\hline Linolenic & Daily & \multicolumn{3}{|c|}{$(---\star---)$} \\
\hline Linolenic & Single & \multicolumn{3}{|c|}{$\left(---^{\star}--\right)$} \\
\hline
\end{tabular}




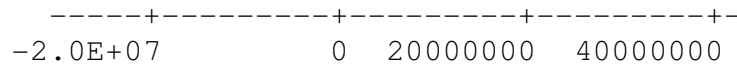

\begin{tabular}{|c|c|c|c|c|}
\hline Treatment & Application & Lower & Center & Upper \\
\hline Atra + Leic & Single & -7719624 & -368754 & 6982117 \\
\hline ATRa +Lenic & Daily & -29935182 & -22584312 & -15233441 \\
\hline ATRa +Lenic & Single & -10991312 & -3640441 & 3710429 \\
\hline control & Daily & -9045311 & -1694440 & 5656430 \\
\hline control & Single & -5555510 & 1795361 & 9146232 \\
\hline dmso control & Daily & -8776519 & -1425648 & 5925222 \\
\hline dmso control & Single & -3470284 & 3880587 & 11231458 \\
\hline Linoleic & Daily & -14032942 & -6682072 & 668799 \\
\hline Linoleic & Single & -7750222 & -399352 & 6951519 \\
\hline Linolenic & Daily & -22496280 & -15145409 & -7794538 \\
\hline Linolenic & Single & -9107172 & -1756302 & 5594569 \\
\hline Treatment & Application & & ---+--- & \\
\hline Atra + Leic & Single & \multicolumn{3}{|c|}{$\begin{aligned}-----+--- \\
(---\star--)\end{aligned}$} \\
\hline ATRa +Lenic & Daily & \multicolumn{3}{|l|}{$(---\star--)$} \\
\hline ATRa +Lenic & Single & \multicolumn{3}{|c|}{$\left(--\star_{-}--\right)$} \\
\hline control & Daily & \multicolumn{3}{|c|}{$(---\star---)$} \\
\hline control & Single & \multicolumn{3}{|c|}{$(---\star---)$} \\
\hline dmso control & Daily & \multicolumn{3}{|c|}{$(--\star---)$} \\
\hline dmso control & Single & \multicolumn{3}{|c|}{$(---\star---)$} \\
\hline Linoleic & Daily & \multicolumn{3}{|c|}{$(---\star--)$} \\
\hline Linoleic & Single & \multicolumn{3}{|c|}{$(---\star--)$} \\
\hline Linolenic & Daily & \multicolumn{3}{|c|}{$\left(--{ }^{\star}---\right)$} \\
\hline Linolenic & Single & \multicolumn{3}{|c|}{$(---\star---)$} \\
\hline & & \multicolumn{3}{|c|}{ 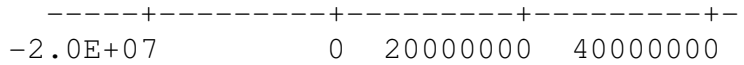 } \\
\hline
\end{tabular}

Treatment $=$ Atra + Leic

Application = Single subtracted from:

\begin{tabular}{|c|c|c|c|c|}
\hline Treatment & Application & Lower & Center & Upper \\
\hline ATRa +Lenic & Daily & -29566429 & -22215558 & -14864687 \\
\hline ATRa +Lenic & Single & -10622558 & -3271688 & 4079183 \\
\hline control & Daily & -8676557 & -1325687 & 6025184 \\
\hline control & Single & -5186756 & 2164115 & 9514985 \\
\hline dmso control & Daily & -8407765 & -1056895 & 6293976 \\
\hline dmso control & Single & -3101530 & 4249341 & 11600211 \\
\hline Linoleic & Daily & -13664189 & -6313318 & 1037553 \\
\hline Linoleic & Single & -7381469 & -30598 & 7320273 \\
\hline Linolenic & Daily & -22127526 & -14776655 & -7425785 \\
\hline Linolenic & Single & -8738419 & -1387548 & 5963323 \\
\hline Treatment & Application & ---- & 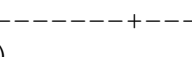 & \\
\hline $\begin{array}{l}\text { ATRa +Lenic } \\
\text { ATRa +Lenic }\end{array}$ & $\begin{array}{l}\text { Dd } \perp \perp y \\
\text { Single }\end{array}$ & $(--$ & $(--\star---)$ & \\
\hline control & Daily & & $(--\star---)$ & \\
\hline control & Single & & $(---\star--$ & \\
\hline dmso control & Daily & & $(--\star---)$ & \\
\hline dmso control & Single & & $(---\star$ & $--)$ \\
\hline Linoleic & Daily & & $(---\star---)$ & \\
\hline Linoleic & Single & & $(---\star---$ & \\
\hline Linolenic & Daily & $(--$ & $\star--)$ & \\
\hline Linolenic & Single & & $(--\star---)$ & \\
\hline
\end{tabular}




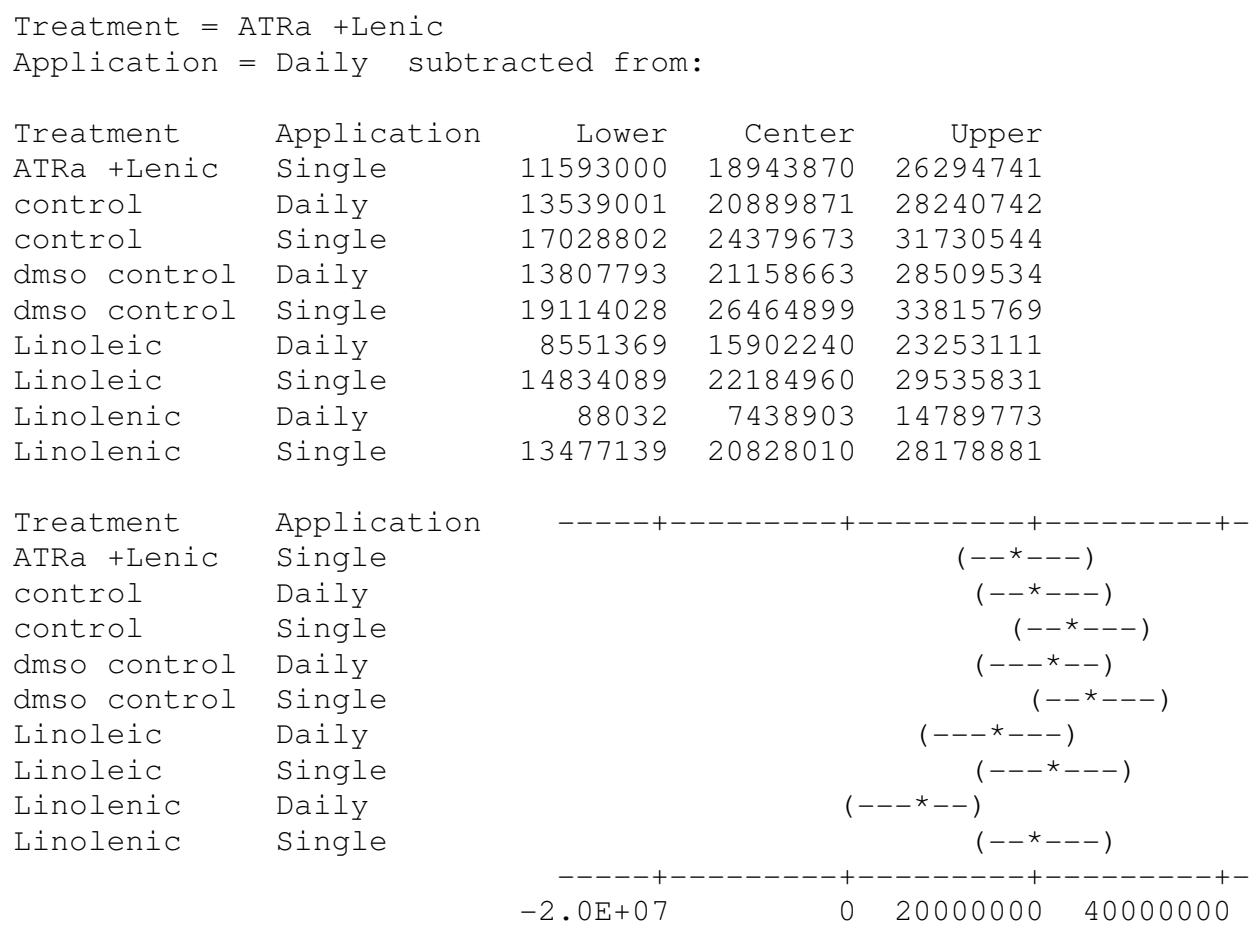

Treatment = ATRa +Lenic

Application = Single subtracted from:

\begin{tabular}{|c|c|c|c|c|}
\hline Treatment & Application & Lower & Center & Upper \\
\hline control & Daily & -5404870 & 1946001 & 9296872 \\
\hline control & Single & -1915068 & 5435802 & 12786673 \\
\hline dmso control & Daily & -5136078 & 2214793 & 9565664 \\
\hline dmso control & Single & 170158 & 7521028 & 14871899 \\
\hline Linoleic & Daily & -10392501 & -3041630 & 4309241 \\
\hline Linoleic & Single & -4109781 & 3241090 & 10591960 \\
\hline Linolenic & Daily & -18855838 & -11504968 & -4154097 \\
\hline Linolenic & Single & -5466731 & 1884140 & 9235010 \\
\hline Treatment & Application & \multirow{2}{*}{\multicolumn{3}{|c|}{$(---\star---)$}} \\
\hline control & Daily & \multirow{2}{*}{\multicolumn{2}{|c|}{$\begin{array}{r}\left(---^{\star}---\right) \\
(---\star--)\end{array}$}} & \\
\hline control & Single & \multicolumn{2}{|c|}{$(---\star--)$} & \\
\hline dmso control & Daily & \multicolumn{3}{|c|}{$(---\star---)$} \\
\hline dmso control & Single & \multicolumn{3}{|c|}{$\left(---\star_{--}\right)$} \\
\hline Linoleic & Daily & \multicolumn{3}{|c|}{$(--\star---)$} \\
\hline Linoleic & Single & \multicolumn{3}{|c|}{$(---\star--)$} \\
\hline Linolenic & Daily & \multicolumn{3}{|c|}{$(--\star---)$} \\
\hline Linolenic & Single & \multicolumn{3}{|c|}{$(---\star---)$} \\
\hline
\end{tabular}

Treatment $=$ control

Application = Daily subtracted from:

$\begin{array}{llrrr}\text { Treatment } & \text { Application } & \text { Lower } & \text { Center } & \text { Upper } \\ \text { control } & \text { Single } & -3861069 & 3489802 & 10840672 \\ \text { dmso control } & \text { Daily } & -7082079 & 268792 & 7619663\end{array}$




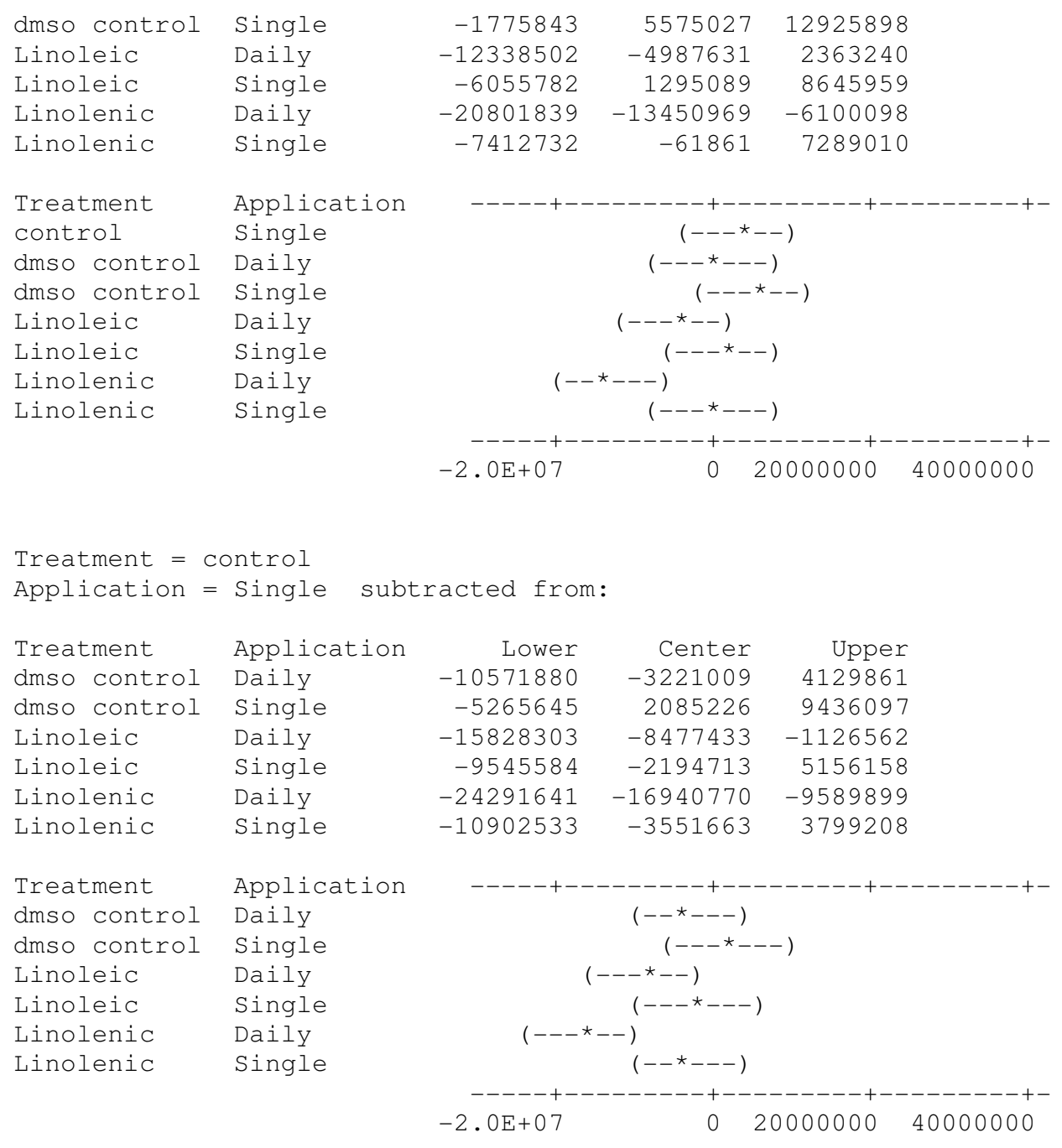

Treatment $=$ dmso control

Application = Daily subtracted from:

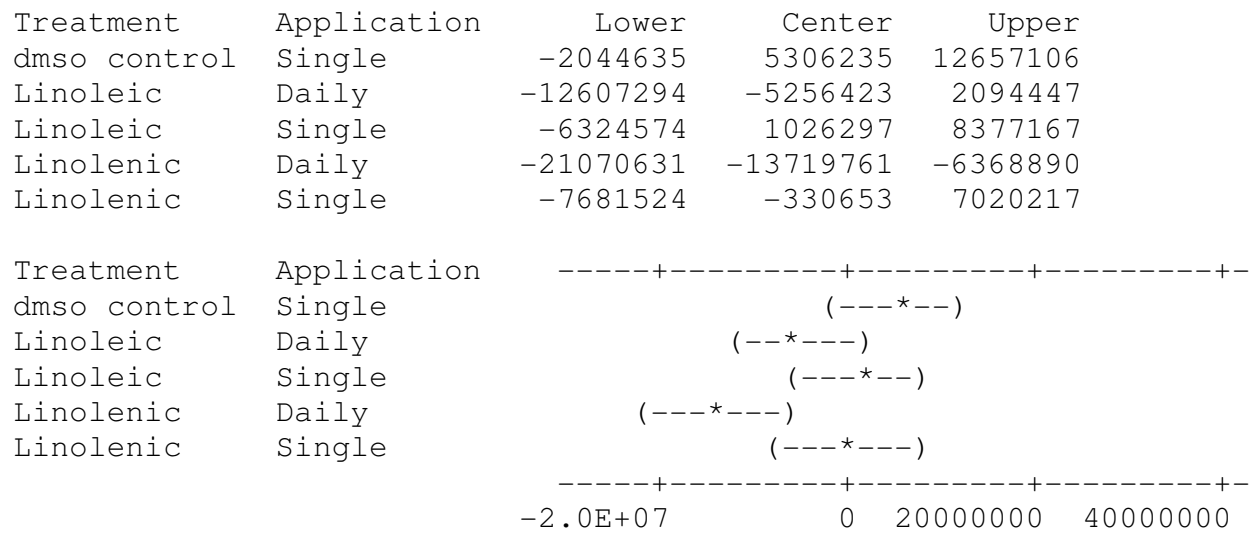

Treatment $=$ dmso control

Application = Single subtracted from: 


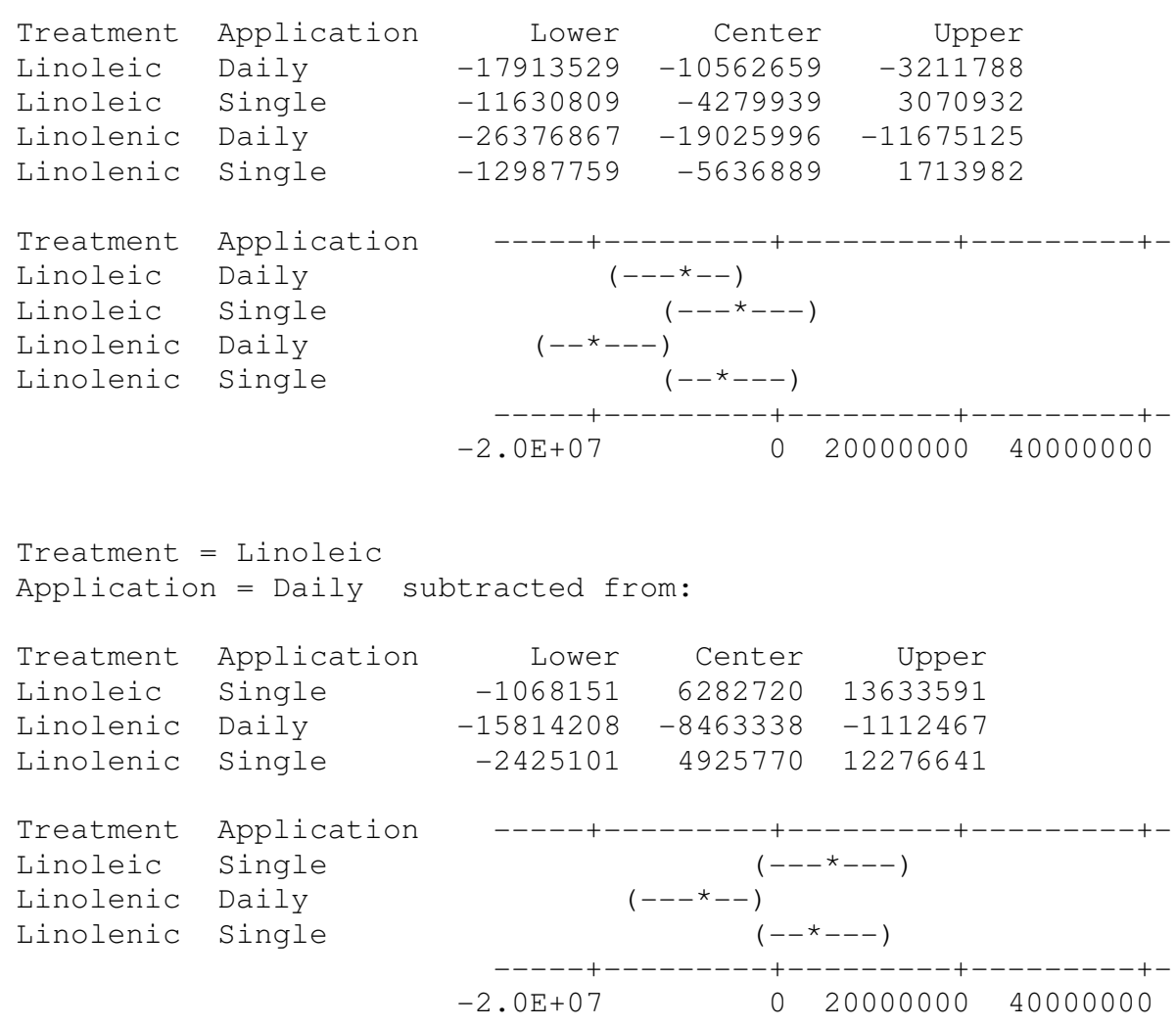

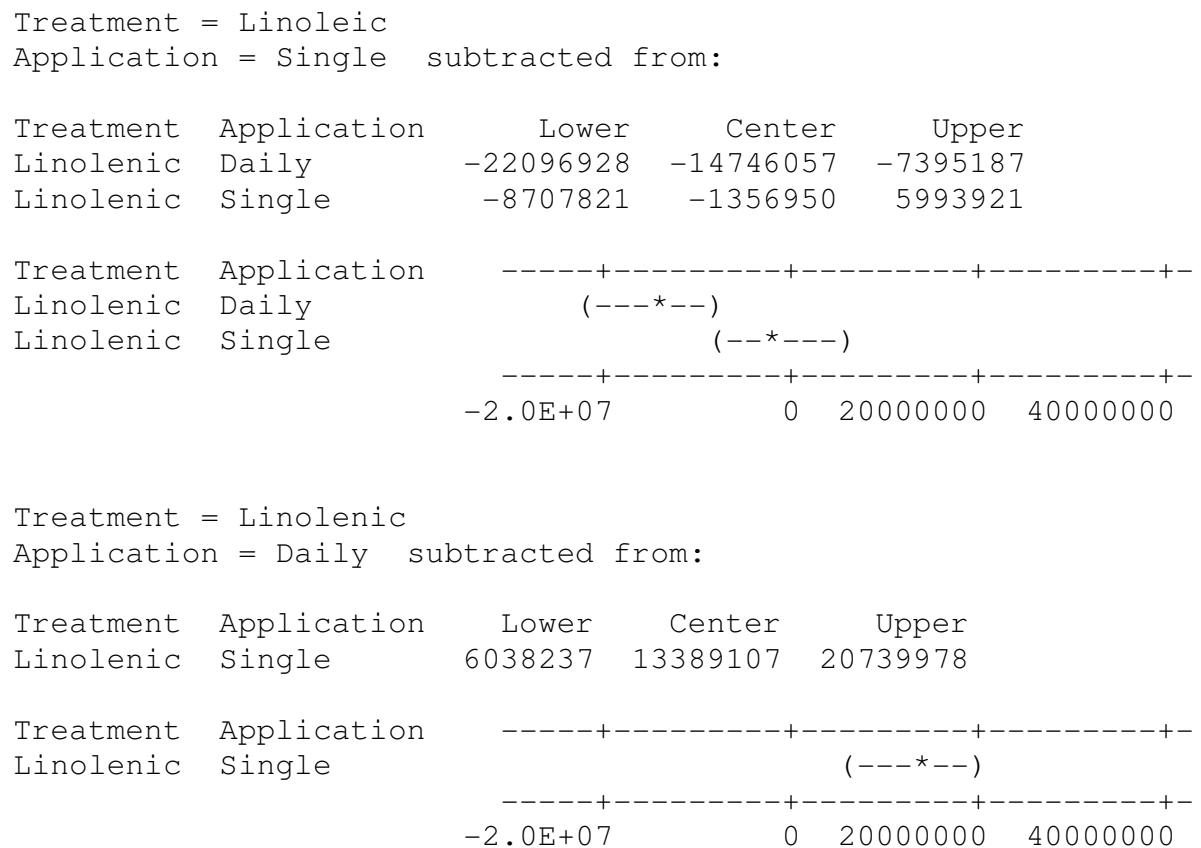




\begin{tabular}{|c|c|c|c|c|c|}
\hline Treatment & Application & $\begin{array}{r}\text { Difference } \\
\text { of Means }\end{array}$ & $\begin{array}{r}\text { SE of } \\
\text { Difference }\end{array}$ & T-Value & $\begin{array}{l}\text { Adjusted } \\
\text { P-Value }\end{array}$ \\
\hline Atra & Single & 17149352 & 2006892 & 8.545 & 0.0000 \\
\hline Atra + Leic & Daily & 18026465 & 2006892 & 8.982 & 0.0000 \\
\hline Atra + Leic & Single & 17657711 & 2006892 & 8.799 & 0.0000 \\
\hline ATRa +Lenic & Daily & -4557847 & 2006892 & -2.271 & 0.58 \\
\hline ATRa +Lenic & Single & 14386023 & 2006892 & 7.168 & 0.0 \\
\hline control & Daily & 16332024 & 2006892 & 8.138 & 0.0000 \\
\hline control & Single & 19821826 & 2006892 & 9.877 & 0.0000 \\
\hline dmso control & Daily & 16600816 & 2006892 & 8.272 & 0.0000 \\
\hline dmso control & Single & 21907052 & 2006892 & 10.916 & 0.00 \\
\hline Linoleic & Daily & 11344393 & 2006892 & 5.653 & 0.0 \\
\hline Linoleic & Single & 17627113 & 2006892 & 8.783 & 0.00 \\
\hline
\end{tabular}

Linolenic Daily $28810562006892 \quad 1.436 \quad 0.9686$

\begin{tabular}{|c|c|c|c|c|c|}
\hline Linolenic & Single & 16270163 & 2006892 & 8.107 & 0.0000 \\
\hline reatment $=$ & Atra & & & & \\
\hline pplication & $=$ Single & racted from: & & & \\
\hline & & Difference & SE of & & Adjusted \\
\hline Treatment & Application & of Means & Difference & T-Value & P-Value \\
\hline Atra + Leic & Daily & 877113 & 2006892 & 0.44 & 1.0000 \\
\hline Atra + Leic & Single & 508359 & 2006892 & 0.25 & 1.0000 \\
\hline ATRa +Lenic & Daily & -21707199 & 2006892 & -10.82 & 0.0000 \\
\hline ATRa +Lenic & Single & -2763328 & 2006892 & -1.38 & 0.9773 \\
\hline control & Daily & -817327 & 2006892 & -0.41 & 1.000 \\
\hline control & Single & 2672474 & 2006892 & 1.33 & 0.982 \\
\hline dmso control & Daily & -548535 & 2006892 & -0.27 & 1.000 \\
\hline dmso control & Single & 4757700 & 2006892 & 2.37 & 0.522 \\
\hline Linoleic & Daily & -5804959 & 2006892 & -2.89 & 0.2386 \\
\hline Linoleic & Single & 477761 & 2006892 & 0.24 & 1.0000 \\
\hline Linolenic & Daily & -14268296 & 2006892 & -7.11 & 0.000 \\
\hline Linolenic & Single & -879189 & 2006892 & -0.44 & 1.000 \\
\hline
\end{tabular}

Treatment $=$ Atra + Leic

Application = Daily subtracted from:

\begin{tabular}{|c|c|c|c|c|c|}
\hline ent & Appl ic & $\begin{array}{l}\text { Difference } \\
\text { of Means }\end{array}$ & $\begin{array}{r}\text { SE of } \\
\text { Difference }\end{array}$ & T-Value & $\begin{array}{r}\text { Adjusted } \\
\text { P-Value }\end{array}$ \\
\hline Atra + Leic & Single & -368754 & 2006892 & -0.18 & 1.0000 \\
\hline ATRa +Lenic & Daily & -22584312 & 2006892 & -11.25 & 0.0000 \\
\hline ATRa +Lenic & Single & -3640441 & 2006892 & -1.81 & 0.8521 \\
\hline control & Daily & -1694440 & 2006892 & -0.84 & 0.9 \\
\hline control & Single & 1795361 & 2006892 & 0.89 & 0.9 \\
\hline dmso control & Daily & -1425648 & 2006892 & -0.71 & 1.0 \\
\hline dmso control & Single & 3880587 & 2006892 & 1.93 & 0.7 \\
\hline Linoleic & Daily & -6682072 & 2006892 & -3.33 & 0.1 \\
\hline Linoleic & Single & -399352 & 2006892 & -0.20 & 1.0 \\
\hline Linolenic & Daily & -15145409 & 2006892 & -7.55 & 0.00 \\
\hline Linolenic & Single & -1756302 & 2006892 & -0.88 & 0.99 \\
\hline \multicolumn{6}{|c|}{ Treatment $=$ Atra + Leic } \\
\hline & & Difference & SE of & & Adjus \\
\hline atment & Application & of Means & Difference & T-Value & $\mathrm{P}-\mathrm{Va}$ \\
\hline$a+$ Lenic & Daily & -22215558 & 2006892 & -11.07 & 0. \\
\hline Ra +Lenic & Single & -3271688 & 2006892 & -1.63 & 0.9 \\
\hline
\end{tabular}




$\begin{array}{llrrrr}\text { control } & \text { Daily } & -1325687 & 2006892 & -0.66 & 1.0000 \\ \text { control } & \text { Single } & 2164115 & 2006892 & 1.08 & 0.9973 \\ \text { dmso control } & \text { Daily } & -1056895 & 2006892 & -0.53 & 1.0000 \\ \text { dmso control } & \text { Single } & 4249341 & 2006892 & 2.12 & 0.6846 \\ \text { Linoleic } & \text { Daily } & -6313318 & 2006892 & -3.15 & 0.1489 \\ \text { Linoleic } & \text { Single } & -30598 & 2006892 & -0.02 & 1.0000 \\ \text { Linolenic } & \text { Daily } & -14776655 & 2006892 & -7.36 & 0.0000 \\ \text { Linolenic } & \text { Single } & -1387548 & 2006892 & -0.69 & 1.0000\end{array}$

Treatment $=$ ATRa +Lenic

Application = Daily subtracted from:

\begin{tabular}{|c|c|c|c|c|c|}
\hline reatment & Applicatio & $\begin{array}{r}\text { Difference } \\
\text { of Means }\end{array}$ & $\begin{array}{r}\text { SE of } \\
\text { Difference }\end{array}$ & T-Value & $\begin{array}{l}\text { Adjusted } \\
\text { P-Value }\end{array}$ \\
\hline ATRa +Lenic & Single & 18943870 & 2006892 & 9.439 & 0.0000 \\
\hline control & Daily & 20889871 & 2006892 & 10.409 & 0.0000 \\
\hline control & Single & 24379673 & 2006892 & 12.148 & 0.0000 \\
\hline dmso control & Daily & 21158663 & 2006892 & 10.543 & 0.0000 \\
\hline mso control & Single & 26464899 & 2006892 & 13.187 & 0.0 \\
\hline inoleic & Daily & 15902240 & 2006892 & 7.924 & 0.0 \\
\hline inoleic & Single & 22184960 & 2006892 & 11.054 & 0.0 \\
\hline Linolenic & Daily & 7438903 & 2006892 & 3.707 & 0.0 \\
\hline Linolenic & Single & 20828010 & 2006892 & 10.378 & 0. \\
\hline \multicolumn{6}{|c|}{ Treatment $=$ ATRa +Lenic } \\
\hline \multicolumn{6}{|c|}{ Application $=$ Single } \\
\hline & & Difference & SE of & & Adjus \\
\hline reatment & Application & of Means & Difference & T-Value & $\mathrm{P}-\mathrm{Va}$ \\
\hline ontrol & Daily & 1946001 & 2006892 & 0.970 & 0.9 \\
\hline ontrol & Single & 5435802 & 2006892 & 2.709 & 0.3 \\
\hline mso control & Daily & 2214793 & 2006892 & 1.104 & 0.9 \\
\hline mso control & Single & 7521028 & 2006892 & 3.748 & 0.0 \\
\hline inoleic & Daily & -3041630 & 2006892 & -1.516 & 0 . \\
\hline noleic & Single & 3241090 & 2006892 & 1.615 & 0.9 \\
\hline nolenic & Daily & -11504968 & 2006892 & -5.733 & 0. \\
\hline inolenic & Single & 1884140 & 2006892 & 0.939 & 0.9 \\
\hline
\end{tabular}

Treatment $=$ control

Application = Daily subtracted from:

$\begin{array}{llrrrr} & & \text { Difference } & \text { SE of } & & \text { Adjusted } \\ \text { Treatment } & \text { Application } & \text { of Means } & \text { Difference } & \text { T-Value } & \text { P-Value } \\ \text { control } & \text { Single } & 3489802 & 2006892 & 1.739 & 0.8842 \\ \text { dmso control } & \text { Daily } & 268792 & 2006892 & 0.134 & 1.0000 \\ \text { dmso control } & \text { Single } & 5575027 & 2006892 & 2.778 & 0.2901 \\ \text { Linoleic } & \text { Daily } & -4987631 & 2006892 & -2.485 & 0.4508 \\ \text { Linoleic } & \text { Single } & 1295089 & 2006892 & 0.645 & 1.0000 \\ \text { Linolenic } & \text { Daily } & -13450969 & 2006892 & -6.702 & 0.0001 \\ \text { Linolenic } & \text { Single } & -61861 & 2006892 & -0.031 & 1.0000\end{array}$

Treatment $=$ control

Application = Single subtracted from:

$\begin{array}{llrrrr} & & \text { Difference } & \text { SE of } & & \text { Adjusted } \\ \text { Treatment } & \text { Application } & \text { of Means } & \text { Difference } & \text { T-Value } & \text { P-Value } \\ \text { dmso control } & \text { Daily } & -3221009 & 2006892 & -1.605 & 0.9303 \\ \text { dmso control } & \text { Single } & 2085226 & 2006892 & 1.039 & 0.9981 \\ \text { Linoleic } & \text { Daily } & -8477433 & 2006892 & -4.224 & 0.0132\end{array}$




\begin{tabular}{|c|c|c|c|c|c|}
\hline Linoleic & Single & -2194713 & 2006892 & -1.094 & 0.9969 \\
\hline Linolenic & Daily & -16940770 & 2006892 & -8.441 & 0.0000 \\
\hline Linolenic & Single & -3551663 & 2006892 & -1.770 & 0.8715 \\
\hline \multicolumn{6}{|c|}{ Treatment $=$ dmso control } \\
\hline \multicolumn{6}{|c|}{ Application = Daily sub } \\
\hline & & Difference & SE of & & Adjus \\
\hline Treatment & Application & of Means & Difference & T-Value & $\mathrm{P}-\mathrm{Val}$ \\
\hline dmso control & Single & 5306235 & 2006892 & 2.644 & 0.3 \\
\hline Linoleic & Daily & -5256423 & 2006892 & -2.619 & 0.372 \\
\hline Linoleic & Single & 1026297 & 2006892 & 0.511 & 1.000 \\
\hline Linolenic & Daily & -13719761 & 2006892 & -6.836 & 0.000 \\
\hline inolenic & Single & -330653 & 2006892 & -0.165 & 1.000 \\
\hline
\end{tabular}

Treatment $=$ dmso control

Application = Single subtracted from:

$\begin{array}{llrrrr} & & \text { Difference } & \text { SE of } & \text { Adjusted } \\ \text { Treatment } & \text { Application } & \text { of Means } & \text { Difference } & \text { T-Value } & \text { P-Value } \\ \text { Linoleic } & \text { Daily } & -10562659 & 2006892 & -5.263 & 0.0010 \\ \text { Linoleic } & \text { Single } & -4279939 & 2006892 & -2.133 & 0.6750 \\ \text { Linolenic } & \text { Daily } & -19025996 & 2006892 & -9.480 & 0.0000 \\ \text { Linolenic } & \text { Single } & -5636889 & 2006892 & -2.809 & 0.2755\end{array}$

Treatment $=$ Linoleic

Application = Daily subtracted from:

$\begin{array}{llrrrr} & & \text { Difference } & \text { SE of } & & \text { Adjusted } \\ \text { Treatment } & \text { Application } & \text { of Means } & \text { Difference } & \text { T-Value } & \text { P-Value } \\ \text { Linoleic } & \text { Single } & 6282720 & 2006892 & 3.131 & 0.1534 \\ \text { Linolenic } & \text { Daily } & -8463338 & 2006892 & -4.217 & 0.0134 \\ \text { Linolenic } & \text { Single } & 4925770 & 2006892 & 2.454 & 0.4698\end{array}$

Treatment $=$ Linoleic

Application = Single subtracted from:

$\begin{array}{llrrrr} & & \text { Difference } & \text { SE of } & \text { Adjusted } \\ \text { Treatment } & \text { Application } & \text { of Means } & \text { Difference } & \text { T-Value } & \text { P-Value } \\ \text { Linolenic Daily } & -14746057 & 2006892 & -7.348 & 0.0000 \\ \text { Linolenic } & \text { Single } & -1356950 & 2006892 & -0.676 & 1.0000\end{array}$

Treatment $=$ Linolenic

Application = Daily subtracted from:

$\begin{array}{llrrrr} & & \text { Difference } & \text { SE of } & \text { Adjusted } \\ \text { Treatment Application } & \text { of Means } & \text { Difference } & \text { T-Value } & \text { P-Value } \\ \text { Linolenic Single } & 13389107 & 2006892 & 6.672 & 0.0001\end{array}$



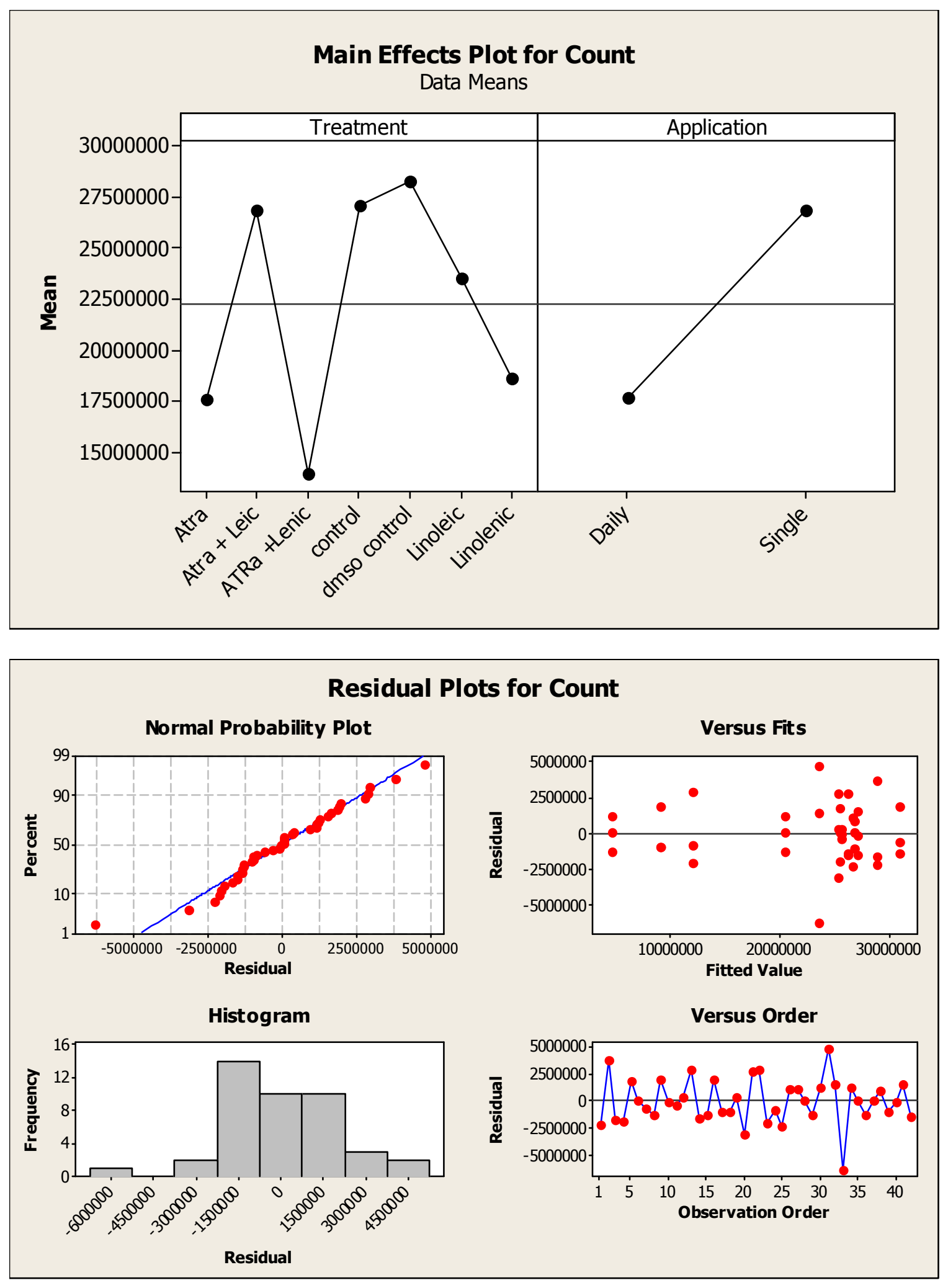